\title{
Assignment of NMR resonances of protons covalently bound to photochemically active cofactors in photosynthetic reaction centers by ${ }^{13} \mathrm{C}-{ }^{1} \mathrm{H}$ photo-CIDNP MAS-J-HMQC experiment
}

\author{
Pavlo Bielytskyi ${ }^{a}$, Daniel Gräsing ${ }^{\text {a }}$, Stefan Zahn ${ }^{\mathrm{b}}$, Kaustubh R. Mote ${ }^{\mathrm{c}}$, A. Alia ${ }^{\mathrm{d}, \mathrm{e}}$, P.K. Madhu ${ }^{\mathrm{c}}$, Jörg Matysik ${ }^{\mathrm{a}, *}$ \\ ${ }^{a}$ Institut für Analytische Chemie, Universität Leipzig, Linnéstraße 3, D-04103 Leipzig, Germany \\ ${ }^{\mathrm{b}}$ Leibniz Institute of Surface Engineering (IOM), Permoserstraße 15, D-04318 Leipzig, Germany

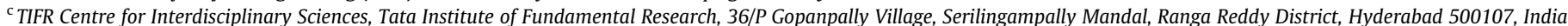 \\ ${ }^{\mathrm{d}}$ Leiden Institute of Chemistry, Leiden University, Einsteinweg 55, 2301 RA Leiden, the Netherlands \\ ${ }^{\mathrm{e}}$ Institut für Medizinische Physik und Biophysik, Universität Leipzig, Härtelstr. 16-18, D-04107 Leipzig, Germany
}

\section{A R T I C L E I N F O}

\section{Article history:}

Received 2 November 2018

Revised 27 November 2018

Accepted 28 November 2018

Available online 29 November 2018

\section{Keywords:}

MAS-J-HMQC

MAS-J-HSQC

HETCOR

Solid-state photo-CIDNP

Bacterial reaction center

\begin{abstract}
A B S T R A C T
Modified versions of through-bond heteronuclear correlation (HETCOR) experiments are presented to take advantage of the light-induced hyperpolarization that occurs on ${ }^{13} \mathrm{C}$ nuclei due to the solid-state photochemically induced dynamic nuclear polarization (photo-CIDNP) effect. Such ${ }^{13} \mathrm{C}-{ }^{1} \mathrm{H}$ photoCIDNP MAS-J-HMQC and photo-CIDNP MAS-J-HSQC experiments are applied to acquire the $2 \mathrm{D}{ }^{13} \mathrm{C}-{ }^{1} \mathrm{H}$ correlation spectra of selectively ${ }^{13} \mathrm{C}$-labeled photochemically active cofactors in the frozen quinoneblocked photosynthetic reaction center (RC) of the purple bacterium Rhodobacter $(R$.) sphaeroides wildtype (WT). Resulting spectra contain no correlation peaks arising from the protein backbone, which greatly simplifies the assignment of aliphatic region. Based on the photo-CIDNP MAS-J-HMQC NMR experiment, we obtained assignment of selective ${ }^{1} \mathrm{H}$ NMR resonances of the cofactors involved in the electron transfer process in the RC and compared them with values theoretically predicted by density functional theory (DFT) calculation as well as with the chemical shifts obtained from monomeric cofactors in the solution. We also compared proton chemical shifts obtained by photo-CIDNP MAS-J-HMQC experiment under continuous illumination with the ones obtained in dark by classical crosspolarization (CP) HETCOR. We expect that the proposed approach will become a method of choice for obtaining ${ }^{1} \mathrm{H}$ chemical shift maps of the active cofactors in photosynthetic RCs and will aid the interpretation of heteronuclear spin-torch experiments.
\end{abstract}

(c) 2018 Elsevier Inc. All rights reserved.

\section{Introduction}

Heteronuclear multidimensional correlation spectroscopy (HETCOR) [1-3] allows for elucidating molecular structures ranging from small organic molecules to polymers and complex biological systems, both in liquid and solid states. The most common variant of this approach is a $2 \mathrm{D}^{1} \mathrm{H}-\mathrm{X}$ HETCOR, in which the correlations between the chemical shifts of protons and ${ }^{13} \mathrm{C},{ }^{15} \mathrm{~N}$ or other nuclei are established. Apart from a molecular structure elucidation, such experiments could be used to obtain information about the hydrogen bonding networks [4], water-protein interactions $[5,6]$, interactions between proteins and cofactors in their binding

\footnotetext{
* Corresponding author.

E-mail address: joerg.matysik@uni-leipzig.de (J. Matysik).
}

pockets [7,8], and electronic structures of amino acids [9,10]. The HETCOR approach is based on the transfer of nuclear polarization between different nuclei either through bonds or through space. In liquid-state NMR, the well-known INEPT technique [11] became an essential building block in many pulse sequences to establish through-bond connections by means of J-couplings. In solid-state, the transfer is traditionally performed exploiting heteronuclear dipolar couplings via cross-polarization (CP) [12]. The solid-state scalar-based experiments were not practical for a long time due to the presence of a strong homonuclear ${ }^{1} \mathrm{H}-{ }^{1} \mathrm{H}$ dipolar couplings leading to line broadening and fast transverse relaxation times. With advances in fast MAS and homonuclear decoupling techniques, the liquid-type J-based experiments emerged also in solid-state NMR [13-16], thus improving the selectivity of the heteronuclear transfers and becoming a necessary tool for the structural investigation of solid-state compounds. However, as is 
common in NMR spectroscopy, such experiments suffer from low sensitivity caused by unfavorable nuclear Boltzmann polarization at thermal equilibrium. Partially this issue could be addressed in the context of indirectly-detected HETCOR experiments, in which low- $\gamma$ nuclei are detected via high- $\gamma{ }^{1} \mathrm{H}$ nucleus [17-20]. While such an approach indeed widened the practical use of 2D correlation spectroscopy, further sensitivity gains are still needed for investigation of a wider span of samples. To overcome the issue of low sensitivity, a range of nuclear hyperpolarization methods has been developed over the years, in which a non-Boltzmann nuclear spin-order is induced by physical or chemical means [21], which also increases the range of possible 2D HETCOR applications. Thus, for example, surface-enhanced NMR by dynamic nuclear polarization (DNP) allows the application of 2D HETCORs for characterization of the functionalized hybrid materials, previously challenging for NMR investigations [22-25]; heteronuclear transfers of photochemically induced dynamic nuclear polarization (photo-CIDNP) could be implemented in the context of HETCOR experiments in liquids for studying amino acids, peptides and proteins in solutions, [26-28], significantly reducing the measurement times.

Photo-CIDNP MAS NMR, relying on the solid-state photo-CIDNP effect, is a member of a family of nuclear hyperpolarization methods. Since its discovery in reaction centers (RCs) from photosynthetic bacteria Rhodobacter (R.) sphaeroides [29], it has been observed in all natural photosynthetic RCs studied so far [30-33], and also in a blue-light photoreceptor, the phototropin mutant LOV1-C57S [34]. In these systems, solid-state photo-CIDNP builds-up during the evolution of the light-induced spin correlated radical pair (SCRP) under the effect of up to three different solidstate mechanisms [35], which have been recently re-interpreted in the concept of level crossings and anti-crossings [36]. Combination of the solid-state photo-CIDNP effect with MAS NMR serves as an analytical tool for studying the electronic structures of photosynthetic cofactors in complex photosynthetic machineries (for review, see [37]). Thus, the molecular electronic structures of cofactors forming the primary SCRP can be resolved in the electronic ground state, the charge separated state, as well as the molecular triplet state [38-40].

Recently, we proposed a novel application of the solid-state photo-CIDNP MAS NMR in the context of a heteronuclear spintorch experiments [41]. In this concept, the light-induced hyperpolarization generated by the solid-state photo-CIDNP effect on ${ }^{13} \mathrm{C}$ or ${ }^{15} \mathrm{~N}$ nuclei of photosynthetic cofactors is transferred to the near-by proton environment by inverse cross polarization resulting in a 2D $\mathrm{X}-{ }^{1} \mathrm{H}$ HETCOR experiment. We expect that such an approach will have a potential to become a tool for exploring the proton environment around the photosynthetic cofactors to understand its role in tuning their properties. However, in order to spot the potential intermolecular transfers of polarization from the cofactors into the surrounding protein pocket, the map of the NMR responses from the protons directly bonded to the cofactors needs to be established first. The complexity of the previously obtained 2D ${ }^{13} \mathrm{C}-{ }^{1} \mathrm{H}$ correlation spectra caused by overlapping proton lines and low dispersion of the ${ }^{13} \mathrm{C}$ resonances from the special pair in the indirect dimension complicated the process of establishing such a map. In the present study, we combine the selectivity provided by the scalar-based HETCORs with the sensitivity offered by the solid-state photo-CIDNP effect. As demonstrated, such a ${ }^{13} \mathrm{C}$ to ${ }^{1} \mathrm{H}$ transfer of light-induced polarization via J-couplings allows us to rationalize the chemical shifts of protons covalently bound to the active cofactors in selectively ${ }^{13} \mathrm{C}$-labeled RCs of $R$. sphaeroides WT through photo-CIDNP MAS-J-HSQC and photo-CIDNP MAS-JHMQC experiments.

\section{Materials and methods}

\subsection{Sample preparation}

The selective ${ }^{13} \mathrm{C}$ labeling of the BChl $a$ and BPhe $a$ cofactors in the reaction center of $R$. sphaeroides WT was achieved by growing bacteria under anaerobic conditions in a medium containing 3-, 4or $5-{ }^{13} \mathrm{C}-\delta$-aminolevulinic acid (3-ALA, 4-ALA, 5-ALA, respectively), as described earlier $[38,42]$. The selectively labeled ${ }^{13} \mathrm{C}-\delta$ aminolevulinic acid $\left(99 \%{ }^{13} \mathrm{C}\right.$ enriched) were purchased from Cambridge Isotope Laboratories. The position of ${ }^{13} \mathrm{C}$ labels in different samples is presented in Fig. 1. The extent of ${ }^{13} \mathrm{C}$ incorporation has been determined as described previously [38]. The total level of incorporation of the ${ }^{13} \mathrm{C}$ label in $\mathrm{BChl} / \mathrm{BPhe}$ was $60 \%( \pm 5 \%)$. Isolation of the RCs was carried out following established protocol [43]. The quinones were removed by incubating the RCs at a concentration of $0.6 \mu \mathrm{M}$ in $4 \% \mathrm{LDAO}, 10 \mathrm{mM}$-phenanthroline, $10 \mathrm{mM}$ Tris buffer, $\mathrm{pH}=8.0$, containing $0.025 \%$ LDAO and $1 \mathrm{mM}$ EDTA [44].

\subsection{NMR spectroscopy}

Photo-CIDNP MAS NMR experiments were performed at 9.4 T (400 MHz ${ }^{1} \mathrm{H}$ Larmor frequency) AVANCE III spectrometer equipped with a 4-mm double resonance MAS probe (Bruker,

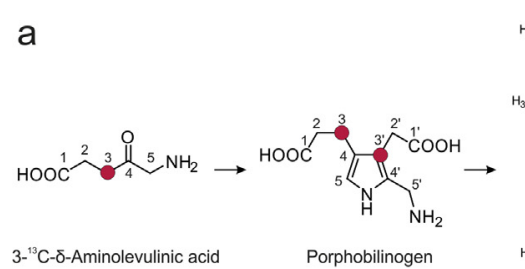

$$
3-{ }^{13} \mathrm{C}-\bar{\delta} \text {-Aminolevulinic acid Porphobilinogen }
$$
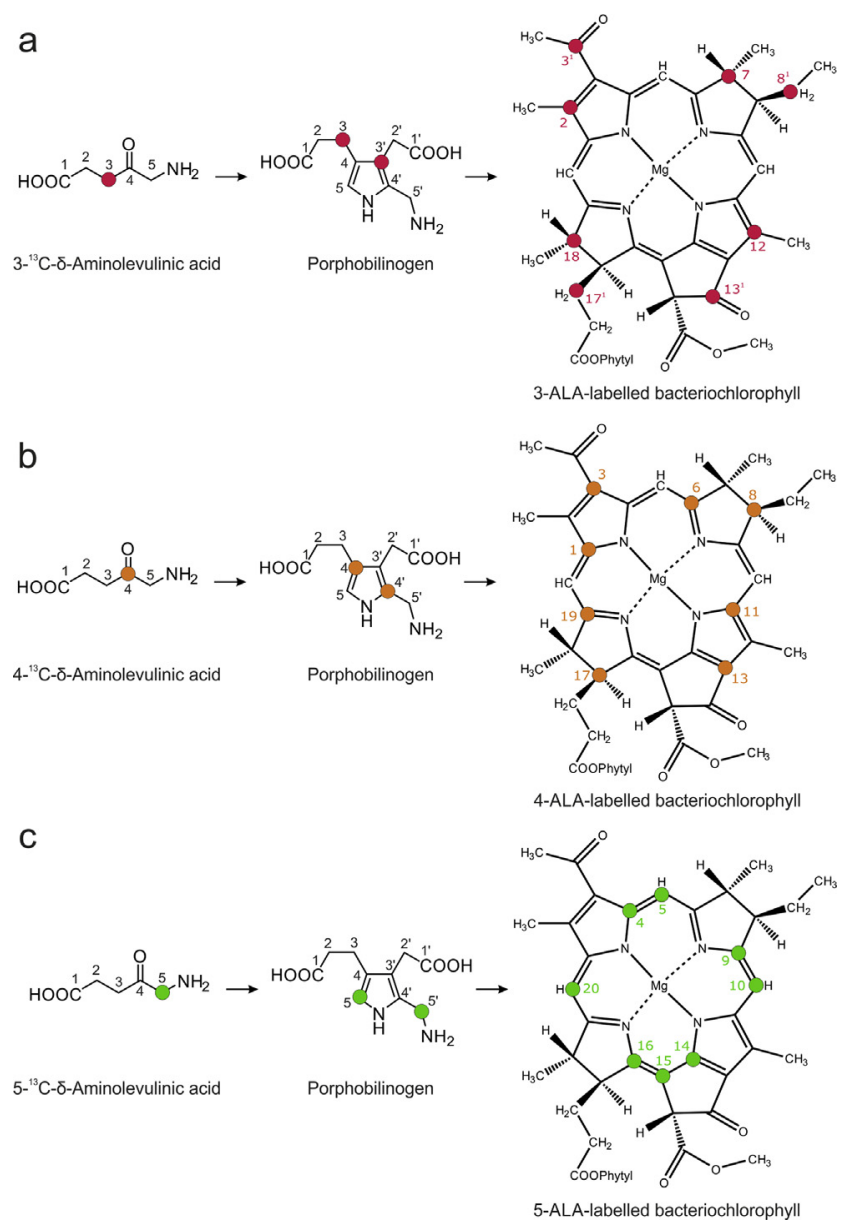

Fig. 1. The biosynthetic pathway for the formation of selective ${ }^{13} \mathrm{C}$-labeled $\mathrm{BChl} a$ by feeding $R$. sphaeroides WT with (a) $3-^{13} \mathrm{C}-\delta$-aminolevulinic acid (3-ALA) (b) $4-{ }^{13} \mathrm{C}$ $\delta$-aminolevulinic acid (4-ALA) and (c) $5-{ }^{13} \mathrm{C}-\delta$-aminolevulinic acid (5-ALA), simplified for clarity. Colored circles represent the positions of ${ }^{13} \mathrm{C}$ isotope labels. The cofactor of BPhe $a$ has an identical labeling pattern. The numbering of carbon atoms is according to the IUPAC convention. 
Karlsruhe, Germany). Approximately $5 \mathrm{mg}$ of ${ }^{13} \mathrm{C}$-labeled RC complexes embedded in LDAO micelles were loaded into transparent 4 -mm sapphire rotors. The samples were frozen in the dark at slow spinning frequency of $400 \mathrm{~Hz}$ to ensure a homogeneous sample distribution against the rotor walls [45]. After freezing, the stable sample temperature of $247 \mathrm{~K}$ was maintained by a temperature control unit. The spinning frequency of $7518 \pm 10 \mathrm{~Hz}$ was regulated by a pneumatic control unit. The idle time of several hours prior to the NMR experiments was needed to equilibrate the temperature of the probe electronics in order to stabilize the ${ }^{1} \mathrm{H}$ radio frequency circuit. The stable ${ }^{1} \mathrm{H}$ wobble curve is crucial as its unaccounted shift might lead to errors during the calibration of the ${ }^{1} \mathrm{H}$ chemical shift axis. Illumination of the sample was achieved by using the continuous illumination setup [46,47]. It comprises a $1000-\mathrm{W}$ xenon-arc lamp with collimation optics, a water filter and glass filters, a focusing element and a light fiber bundle. The xenon arc lamp emits a sunlight-like spectrum covering a wide range of frequencies from the UV to the IR. The water filter cuts off the IR frequencies and prevents the disturbance of the spinning speed counter, working in the near-IR region. The UV part of the emission spectrum is removed by a set of glass filters. A fiber bundle is used to transfer the radiation from the collimation optics to the sample. A mechanical shutter is incorporated into the setup to assure a defined illumination time. Optimized ${ }^{1} \mathrm{H}$ and ${ }^{13} \mathrm{C} 90^{\circ}$ pulse lengths were 2.5 and $3.0 \mu \mathrm{s}$, respectively. The ${ }^{13} \mathrm{C}$ NMR spectra were referenced to the $\mathrm{COOH}$ response of solid L-tyrosine hydrochloride at $172.1 \mathrm{ppm}$. The data were processed with Bruker TopSpin 3.2 and plotted with MNova 12 (Mestrelab Research, S. L. Santiago de Compostela, Spain).

\subsection{Optimization of homonuclear decoupling}

During heteronuclear transfer delays $\tau$ and $\tau^{\prime}$ (see Fig. 2), and also $t_{1}$ evolution period, supercycled-phase-modulated Lee-
Goldburg homonuclear decoupling (PMLG5-S2) [48,49] was implemented. Each PMLG5 block consisted of 10 pulses with the following phases: $339.22^{\circ}, 297.65^{\circ}, 256.08^{\circ}, 214.51^{\circ}, 172.94^{\circ}, 352.94^{\circ}$, $34.51^{\circ}, 76.08^{\circ}, 117.65^{\circ}, 159.22^{\circ}$ ( $\mathrm{m} 5 \mathrm{~m}$ shape in TopSpin 3.2 library). A consecutive PMLG5 block was then repeated with $180^{\circ}$ phase shift to complete S2 supercycle. The PMLG5 ${ }^{1} \mathrm{H}$ pulse length of $1.33 \mu \mathrm{s}$, RF amplitude of $88 \mathrm{kHz}$ and $4000 \mathrm{~Hz}{ }^{1} \mathrm{H}$ offset during homonuclear decoupling were used which were optimized by observing the $J$-splitting in adamantane powder by using a PMLG5-S2-decoupled CPMAS experiment, and further fineoptimized by monitoring the splitting between the methylene protons of natural abundance solid glycine in the indirect dimension in ${ }^{1} \mathrm{H}\{\mathrm{PMLG} 5-\mathrm{S} 2\}-{ }^{1} \mathrm{H}\{$ wPMLG5-S2 $\}$ homonuclear correlation experiment [50]. The scaling factor of 0.32 was then calculated by dividing the observed difference between the center of the methylene signals and the $\mathrm{NH}_{3}$ signal in the indirect dimension to the expected difference of $4.84 \mathrm{ppm}$. The appropriately scaled ${ }^{1} \mathrm{H}$ indirect dimension was referenced by assigning the midpoint of two methylene proton peaks of solid glycine to $3.52 \mathrm{ppm}$. Swept-frequency two-pulse phase-modulation (SW $\mathrm{f}_{\mathrm{f}}$-TPPM) heteronuclear decoupling [51] with $100 \mathrm{kHz}$ RF amplitude was used during the ${ }^{13} \mathrm{C}$ acquisition.

\subsection{D HETCOR experiments}

The $\tau$ and $\tau^{\prime}$ delays (see Fig. 2) were optimized directly on the sample of interest by finding the best signal intensity through 1D MAS-J-HMQC and 1D MAS-J-HSQC-edited experiments. The $\tau$ delay was synchronized to be an integer number of rotor periods with the smallest rotor-synchronized increment $\Delta \tau=\Delta \tau^{\prime}=133 \mu \mathrm{s}$. The optimized $\tau$ delays were $1.86 \mathrm{~ms}$ in photo-CIDNP MAS-J-HMQC and $\tau=\tau^{\prime}=0.93 \mathrm{~ms}$ in photo-CIDNP MAS-J-HSQC experiments on protein samples.

a

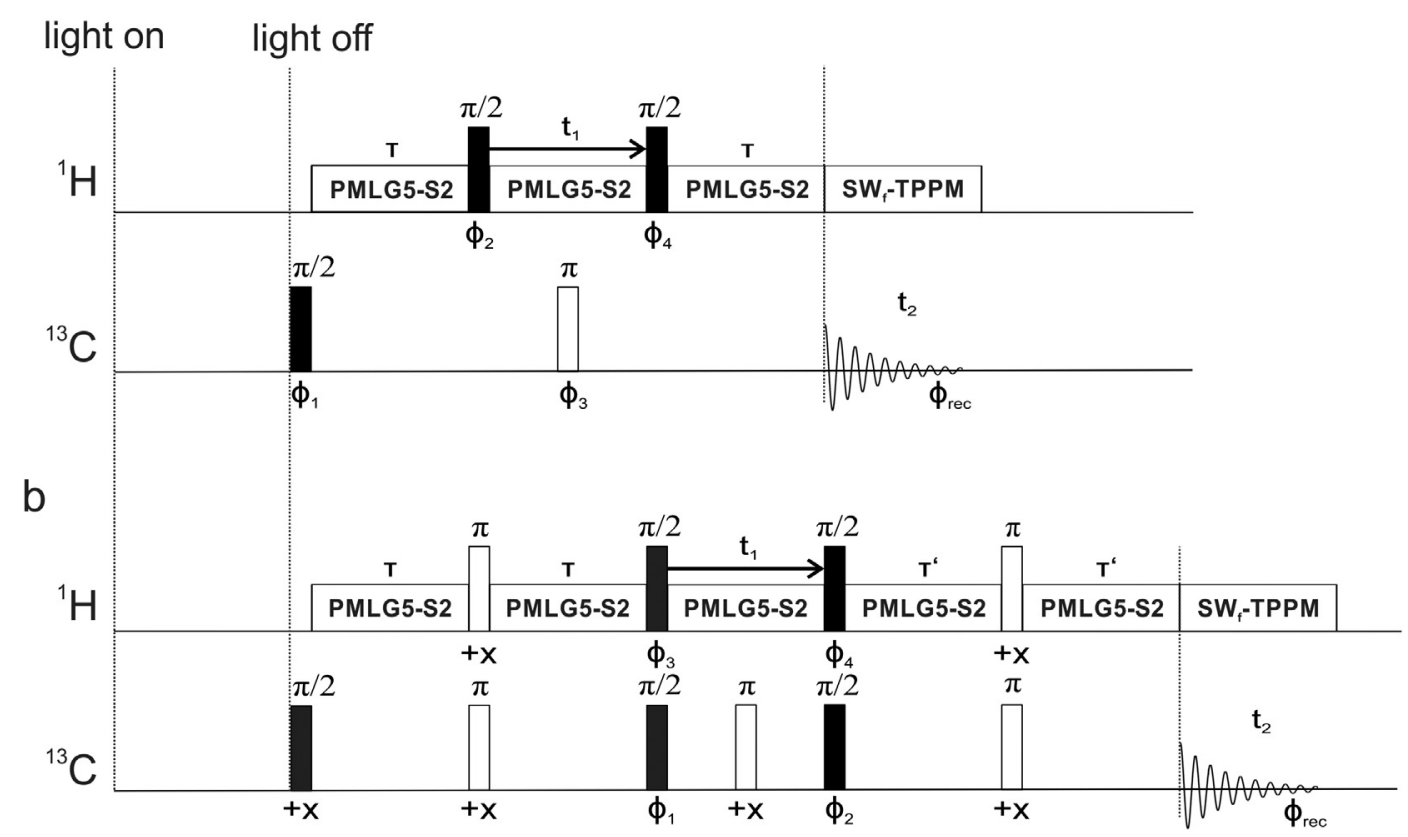

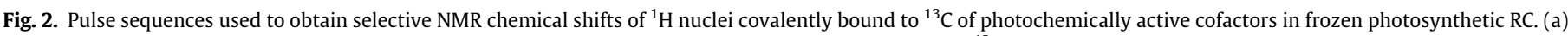

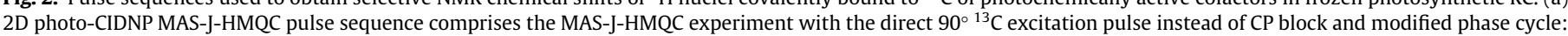

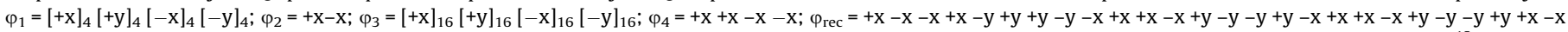

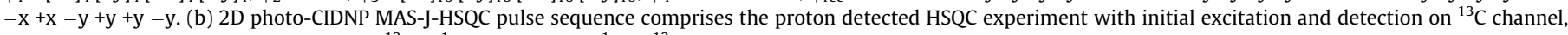

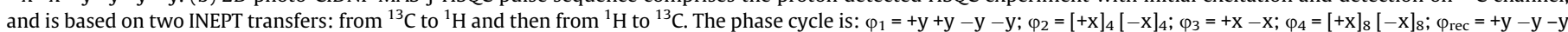

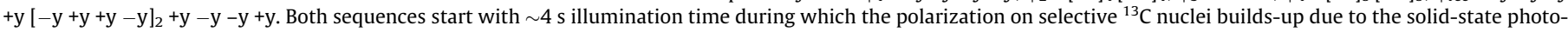
CIDNP effect. 
The 2D photo-CIDNP spectra were recorded with $64 t_{1}$ increments, accumulating 1024 scans in each indirect slice with relaxation delay of $4 \mathrm{~s}$, resulting in 3 days of experimental time. Frequency discrimination during the evolution period was achieved with TPPI [52]. A $45^{\circ}$ shifted squared sine bell window function (qsine SSB $=4$ in TopSpin) was applied in the indirect dimension, and further zero-filled to 1024 points prior to Fourier transformation. A $90^{\circ}$ shifted squared sine bell window function (qsine SSB $=2$ ) was applied in the direct dimension and zerofilled to 4096 data points.

\subsection{NMR experiments at high magnetic field}

High-field NMR experiments were performed at $20 \mathrm{~T}(850 \mathrm{MHz}$ ${ }^{1} \mathrm{H}$ Larmor frequency) AVANCE III spectrometer equipped with 4$\mathrm{mm}$ triple resonance MAS probe (Bruker, Karlsruhe, Germany). The sample was loaded into a 4-mm zirconia rotor, slowly frozen down to $250 \mathrm{~K}$ and spun at $12333 \pm 3 \mathrm{~Hz}$ MAS frequency in the dark. Optimized ${ }^{1} \mathrm{H} 90^{\circ}$ pulse length was $3.0 \mu \mathrm{s}$. CP was optimized to satisfy $n= \pm 1$ Hartmann-Hahn $(\mathrm{HH})$ condition with $80 \%$ ramp on ${ }^{1} \mathrm{H}$ and $55 \mathrm{kHz}{ }^{13} \mathrm{C}$ lock field, $250 \mu$ s contact time was used [53]. 2D CP HETCOR experiment was recorded with pulse sequence similar to Fig. S1a with non-supercycled-phase-modulated Lee-Goldburg homonuclear decoupling (PMLG5) which was used during $t_{1}$ evolution period; additional $1.82 \mu \mathrm{s}$ magic-angle (MA) pulses were applied before and after $t_{1}$ period of homonuclear decoupling to consider the tilted precession of proton magnetization, which is not compensated due to the absence of the supercycle. Decoupling optimization was done on adamantane as described above. PMLG pulse was $2.1 \mu \mathrm{s}$ with $83 \mathrm{kHz} \mathrm{RF}$ amplitude and an offset of $-1500 \mathrm{~Hz}$. The scaling factor of 0.5 was determined by comparing the experimental J-coupling values $\left(\mathrm{J}\left(\mathrm{CH}_{2}\right)=65.2 \mathrm{~Hz}, \mathrm{~J}(\mathrm{CH})\right.$ $=65.7 \mathrm{~Hz}$ ) with the known J-coupling values [54] of adamantane

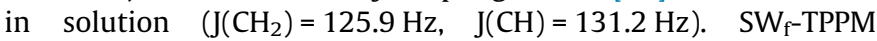
heteronuclear decoupling with $83 \mathrm{kHz} \mathrm{RF}$ amplitude was used during ${ }^{13} \mathrm{C}$ acquisition. The ${ }^{13} \mathrm{C}$ NMR spectra were referenced to the $\mathrm{COOH}$ response of solid L-tyrosine hydrochloride at $172.1 \mathrm{ppm}$. A $45^{\circ}$ shifted squared sine bell window function (qsine SSB $=4$ in TopSpin) was applied in the indirect dimension, and further zerofilled to 1024 points prior to Fourier transformation. A $90^{\circ}$ shifted squared sine bell window function (qsine $\mathrm{SSB}=2$ ) was applied in the direct dimension and zero-filled to 4096 data points.

\subsection{Pulse sequences for photo-CIDNP MAS-J-HMQC and MAS-J-HSQC experiments}

Photo-CIDNP MAS-J-HMQC pulse sequence is presented in Fig. 2a. It comprises previously reported CP MAS-J-HMQC sequence [13] with a few modifications. It starts with a short delay of $\sim 4 \mathrm{~s}$ during which the sample is illuminated and polarization buildsup on selective ${ }^{13} \mathrm{C}$ nuclei due to solid-state photo-CIDNP effect. A defined illumination period is provided with mechanical shutter triggered via pulse program. ${ }^{1} \mathrm{H}$-to- ${ }^{13} \mathrm{C} \mathrm{CP}$ is substituted with direct $90^{\circ}$ excitation pulse that creates in-phase ${ }^{13} \mathrm{C}$ magnetization. This magnetization evolves for a defined time $\tau$ under the isotropic scaled heteronuclear $\mathrm{J}_{\mathrm{CH}}$ coupling into anti-phase magnetization for a pair of covalently bound ${ }^{13} \mathrm{C}-{ }^{1} \mathrm{H}$ nuclei, while strong ${ }^{1} \mathrm{H}-{ }^{1} \mathrm{H}$ dipolar couplings are removed to a certain extent by means of PMLG5-S2 homonuclear decoupling. The first $90^{\circ}$ proton pulse excites MQ coherences that evolve during period $t_{1}$ under the scaled proton chemical shift. The second $90^{\circ}$ proton pulse converts MQ into ${ }^{13} \mathrm{C}$ anti-phase coherence which evolves back into in-phase observable coherence during the second $\tau$ delay. Appropriate phase cycle ensures filtering out ${ }^{13} \mathrm{C}$ magnetization that is present at the end of the pulse sequence due to the direct excitation pulse.
Photo-CIDNP MAS-J-HSQC pulse sequence is presented in Fig. 2b. It comprises the liquid-state proton detected HSQC experiment [55] with homonuclear ${ }^{1} \mathrm{H}$ decoupling introduced during $\tau$, $\tau^{\prime}$ and $t_{1}$ [15] and with initial excitation and detection placed on ${ }^{13} \mathrm{C}$ channel. The pulse sequence starts with a short delay of $\sim 4 \mathrm{~s}$ during which the sample is illuminated and polarization buildsup on selective ${ }^{13} \mathrm{C}$ nuclei due to solid-state photo-CIDNP effect. After initial $90^{\circ}$ excitation pulse, the magnetization from ${ }^{13} \mathrm{C}-{ }^{1} \mathrm{H}$ pair evolves into anti-phase ${ }^{13} \mathrm{C}$ coherence during first $\tau-\pi-\tau$ period under the effect of scaled $\mathrm{J}_{\mathrm{CH}}$ coupling and is converted into proton anti-phase coherence by the $90^{\circ}$ applied on both channels simultaneously (first INEPT transfer). The single-quantum (SQ) ${ }^{1} \mathrm{H}$ coherence evolves during the period of $t_{1}$ under the scaled proton chemical shift and is converted back to ${ }^{13} \mathrm{C}$ anti-phase coherence by second set of simultaneous $90^{\circ}$ pulses (second INEPT). Finally, during the $\tau^{\prime}-\pi-\tau^{\prime}$ period the anti-phase ${ }^{13} \mathrm{C}$ coherence evolves into detectable in-phase ${ }^{13} \mathrm{C}$ magnetization.

\section{Results and discussion}

\subsection{D photo-CIDNP MAS-J-HMQC experiments}

The standard photo-CIDNP MAS NMR experiment under continuous illumination comprises Hahn-echo pulse sequence and is described elsewhere [47]. We first performed such experiments on RCs from $R$. sphaeroides WT with different ${ }^{13} \mathrm{C}$ isotope labeling pattern. The spectra obtained under continuous illumination for 3-ALA, 4-ALA and 5-ALA labeled RCs are shown in Fig. 3(b, e, h), and the corresponding dark spectra in Fig. 3(a, d, g), respectively. The light spectra consist of series of light-induced signals with emissive (negative) character, and could be assigned to the response from ${ }^{13} \mathrm{C}$ labels of the electron donor (two $\mathrm{BChl} a$ molecules $\mathrm{P}_{\mathrm{L}}$ and $\mathrm{P}_{\mathrm{M}}$, see Supplementary Fig. S4) and electron acceptor (BPhe $a$ molecule $\Phi_{\mathrm{A}}$ ), forming the SCRP upon light excitation. Such emissive pattern of light-induced signals has been previously explained by the dominance of the three-spin-mixing (TSM) mechanism over the differential decay (DD) [56] during the evolution of SCRP. Several absorptive (positive) signals in the aliphatic region that emerge also on dark spectra are attributed to the signature of the detergent and the response from the saturated carbons of the protein.

We then applied the pulse sequence in Fig. 2a to record 1D photo-CIDNP MAS-J-HMQC spectra of corresponding labeled samples, and the result is shown in Fig. 3(c, f, i). All spectra contain notably fewer peaks as compared to standard photo-CIDNP MAS NMR experiments. Thus, the 3-ALA spectrum consists of several peaks in the region between 19 and $55 \mathrm{ppm}$, which correspond to signals from carbons C-7, C-18, C- ${ }^{1}$ and C- $17^{1}$ [57]. The 4-ALA spectrum consists of peaks in the region between 40 and $60 \mathrm{ppm}$ typical for carbons C-8 and C-17 [38]. Finally, the 5-ALA spectrum shows signals in the region between 90 and $110 \mathrm{ppm}$, characteristic of the response from the methine carbons $\mathrm{C}-5, \mathrm{C}-10$ and $\mathrm{C}-20$ [58].

The common feature between all the listed carbons producing signals in 1D photo-CIDNP MAS-J-HMQC-edited spectra is that they all have covalently bound protons attached to them. On the other hand, all signals from quaternary carbons are effectively silenced, which is the expected outcome from the MAS-J-HMQC experiment [13]. Indeed, in order for the MAS-J-HMQC experiments to perform, the presence of the scalar $\mathrm{J}_{\mathrm{CH}}$ couplings to create heteronuclear MQ coherences is required. Unlike CP-based dipolar transfer with moderate contact times, this method yields highly selective spectra. The absence of undesirable signals from quaternary carbons that might arise from the ${ }^{13} \mathrm{C}$ coherences generated by the direct excitation confirms the effectiveness of the phase 


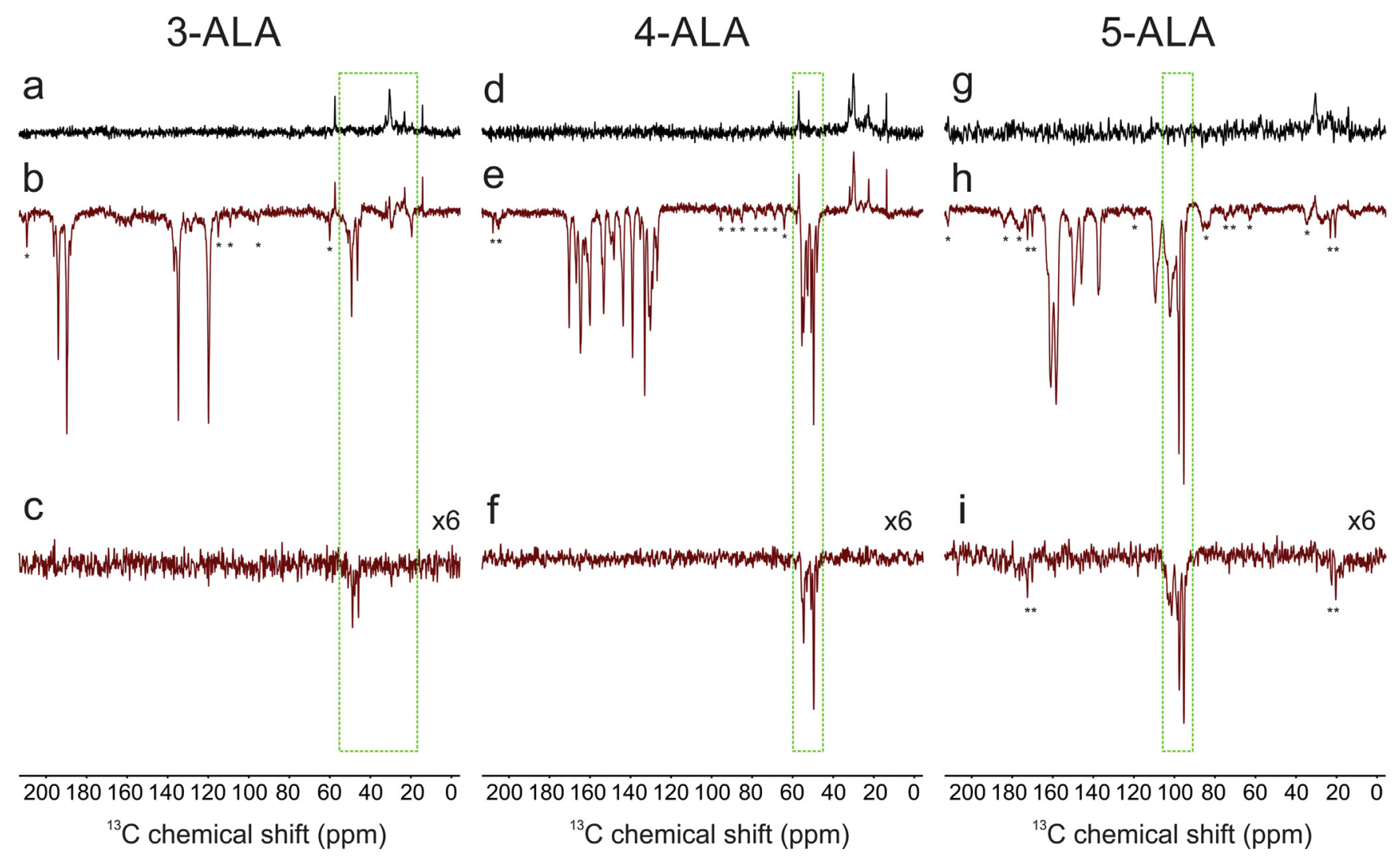

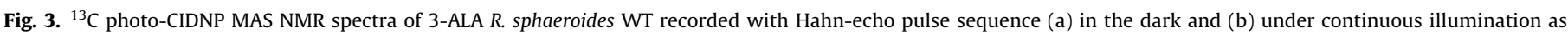

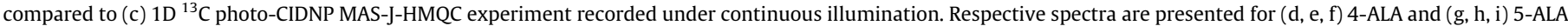

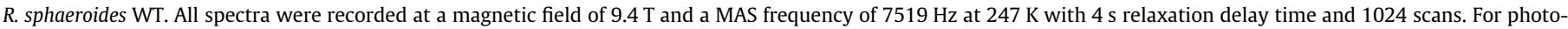

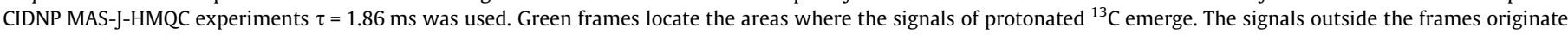

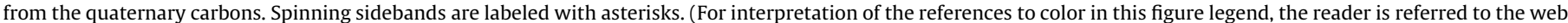
version of this article.)

cycle. Also, since the recovery of the solid-state photo-CIDNP generated signals is faster than the $T_{1}$ limit [59], the short recycle delay times typical for $\mathrm{CP}$-based experiments with ${ }^{1} \mathrm{H}$ excitation, could be used for the direct excitation of ${ }^{13} \mathrm{C}$ nuclei. Within $4 \mathrm{~s}$ already $\sim 50 \%$ of steady-state photo-CIDNP signal is reached. Thus, 4 s recycle delay time was empirically found to be optimal for majority of ${ }^{13} \mathrm{C}$ photo-CIDNP MAS NMR experiments.

Currently, the photo-CIDNP MAS-J-HMQC experiment provides $\sim 4.5$ times lower $\mathrm{S} / \mathrm{N}$ as compared to a standard photo-CIDNP MAS NMR. The transfer efficiency in MAS-J-HMQC experiment depends on the chosen $\tau$ delay, which is different for carbons with different multiplicity [13]. In all our experiments, the $\tau=1.86 \mathrm{~ms}$ was found to be the best for all samples to obtain the highest intensity for $\mathrm{CH}$ groups. Additionally, the signal intensity depends on the transverse $T_{2}{ }^{\prime} \mathrm{H}$ and $T_{2}{ }^{\prime} \mathrm{C}$ relaxation times. During $\tau$ delays the presence of ${ }^{1} \mathrm{H}-{ }^{1} \mathrm{H}$ homonuclear dipolar couplings leads to a fast decoherence of ${ }^{1} \mathrm{H}$ and ${ }^{13} \mathrm{C}$ magnetization. The combination of fast MAS and homonuclear decoupling schemes significantly improves the lifetimes of transverse proton and carbon coherences. In particular, the PMLG5 has been proven to be efficient for prolonging the proton and carbon $T_{2}{ }^{\prime}$ times at high spinning frequencies [16]. While the supercycled version of PMLG5 provided the longest $T_{2}^{\prime}$ times, the non-supercycled variant was reported to be the most efficient for INEPT-type of transfer [16]. From our experience, the supercycled PMLG5-S2 showed better performance for photo-CIDNP MAS-J-HMQC experiment. However, we expect that the transfer efficiency might be further improved by implementing higher MAS frequencies, which would further prolong the $T_{2}{ }^{\prime} \mathrm{H}$ and $T_{2}{ }^{\prime} \mathrm{C}$ times due to more efficient averaging of homonuclear ${ }^{1} \mathrm{H}-{ }^{1} \mathrm{H}$ couplings and provide more flexibility in choosing the experimental parameters while keeping the rotor synchronization of $\tau$ delays.

Considering that a high-quality $1 \mathrm{D}{ }^{13} \mathrm{C}$ photo-CIDNP MAS NMR spectrum can be obtained by 128 scans in less than 10 min due to the strong signal enhancement (factors of $10,000-80,000$ for ${ }^{13} \mathrm{C}$ ) $[37,40]$, it is possible to obtain an informative 1D photo-CIDNP MAS-J-HMQC-edited spectrum with $1 \mathrm{k}$ scans within $\sim 1 \mathrm{~h}$, which makes this experiment very applicable for spectral editing and for assignment of protonated carbons of photosynthetic cofactors.

\section{2. $2 D$ photo-CIDNP MAS-J-HMQC experiments and comparison to $2 D$ photo-CIDNP MAS-J-HSQC}

The performance of the carbon-proton 2D photo-CIDNP MAS-JHMQC pulse sequence was first tested on a $\mathrm{u}^{13}{ }^{13} \mathrm{C}$ labeled L-alanine standard sample as compared to other carbon-proton dipolar- and scalar-based HETCORs. This sample has a fast ${ }^{13} \mathrm{C}$ spin lattice relaxation allowing for relatively short recycle delay times in the experiments with direct carbon excitation. The resulting 2D spectra are presented in the in supporting information as Fig. S2. Overall, the absence of artifacts and similar performance compared to standard MAS-J-HMQC sequence was confirmed.

The carbon-proton 2D photo-CIDNP MAS-J-HMQC spectra of 5ALA, 4-ALA and 3-ALA labeled RCs are present in Fig. 4(a-c, respectively). The $\mathrm{CH}$ and $\mathrm{CH}_{2}$ carbons are correlated with their attached protons whereas the quaternary carbons do not show any crosspeaks in the F1 dimension, which confirms the high selectivity of one-bond-type transfers. The design of the experiment allows the direct detection of ${ }^{13} \mathrm{C}$ resonances in the $\mathrm{F} 2$ dimension, thus 

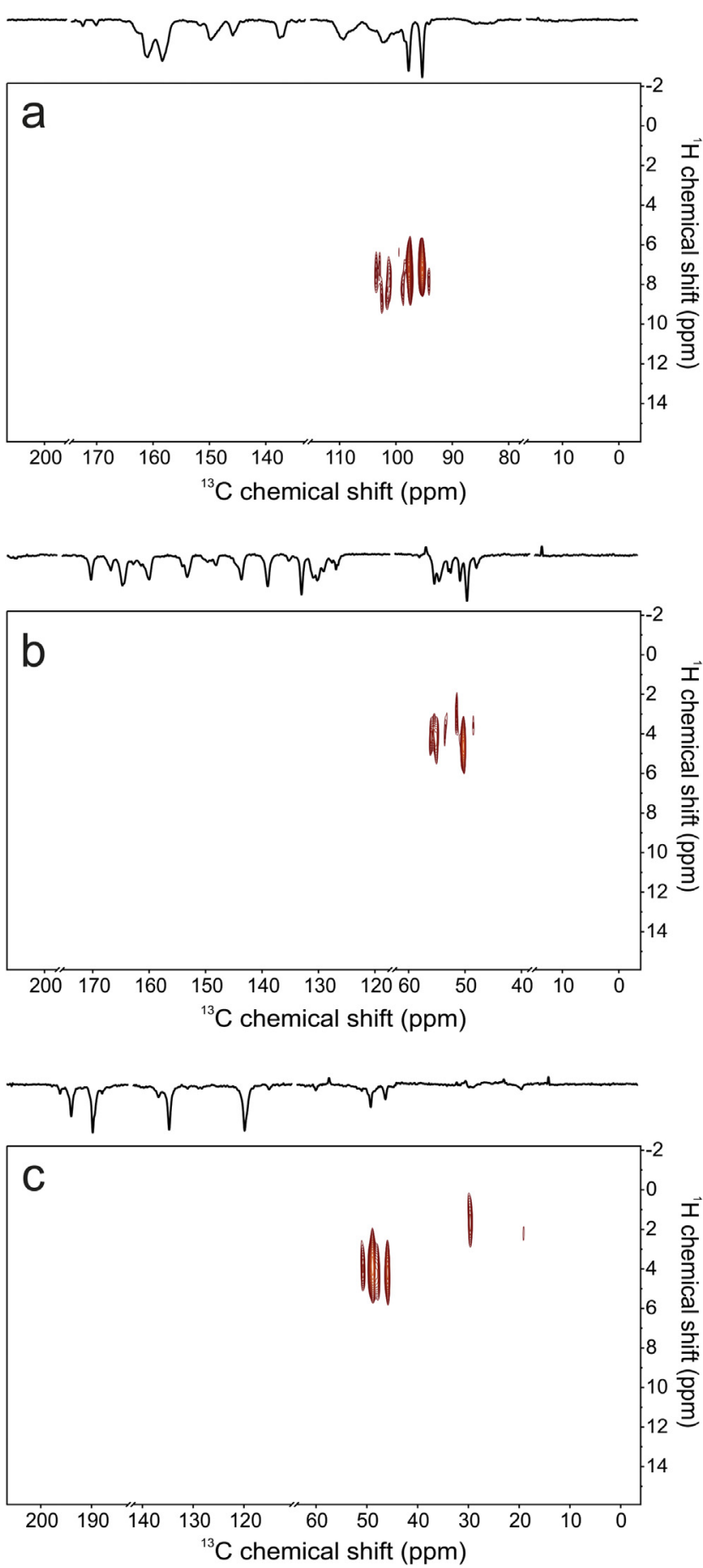

Fig. 4. 2D photo-CIDNP MAS-J-HMQC spectra of (a) 5-ALA (b) 4-ALA and (c) 3-ALA R. sphaeroides WT recorded under continuous illumination at magnetic field of $9.4 \mathrm{~T}$, $7519 \mathrm{~Hz}$ MAS frequency and temperature of $247 \mathrm{~K}$. Each spectrum was recorded with $4 \mathrm{~s}$ relaxation delay, $\tau=1.86 \mathrm{~ms}$, and $64 \mathrm{t}_{1}$ increments accumulating 1024 scans in each indirect slice, resulting in 3 days of measurement time per spectrum.

discrimination between the individual ${ }^{13} \mathrm{C}$ signals originating from both halves of the special pair and the acceptor is possible, despite their low spectral dispersion. Notably, since solid-state photoCIDNP effect is generated exclusively on the cofactors forming the SCRP during the electron transfer process, the spectra contain no correlation peaks arising from the protein backbone, which greatly simplifies the assignment of aliphatic region. This in particular is important for assignment of 3-ALA and 4-ALA RCs, whose protonated carbons generate the signals in the region between 15 and
$60 \mathrm{ppm}$ and otherwise would have been hidden under the strong aliphatic backbone response. Such overlap could not be otherwise resolved even with classical CP-MAS-J-HMQC, which still generates 1-bond $\mathrm{CH}$ correlations for aliphatic carbons in the upfield region [15]. The common approach to suppress the natural abundance background signals would be application of double-quantum filters $[60,61]$. However, this would imply significant loss of signal intensity and the need of presence of homonuclear ${ }^{13} \mathrm{C}-{ }^{13} \mathrm{C}$ pairs in the labeled pattern, which is not feasible in the current strategies for labeling of photosynthetic cofactors with ALA.

Despite the discussed advantages, the MAS-J-HMQC sequence might suffer from the presence of unresolved homonuclear carbon-carbon couplings, which are active on MQ coherences. This includes the scalar JCC couplings in excitation and reconversion blocks and residual homonuclear ${ }^{13} \mathrm{C}-{ }^{13} \mathrm{C}$ dipolar couplings during $t_{1}$, both leading to the attenuation of the signal and broadening of the proton lines in F1 dimension for MAS-J-HMQC. On the other hand, these couplings do not affect SQ coherences. It was reported, therefore, that the MAS-J-HSQC experiment has an advantage over MAS-J-HMQC for fully labeled samples $[14,15]$. While in 3- and 4ALA labeling patterns, all ${ }^{13} \mathrm{C}$ labels are isolated and therefore should not be affected by homonuclear ${ }^{13} \mathrm{C}-{ }^{13} \mathrm{C}$ couplings, the 5 ALA RC has several ${ }^{13} \mathrm{C}$ pairs in the proximity of a single bond. Thus, the signals from protonated $\mathrm{C}-5$ and $\mathrm{C}-10$ were expected to improve by implementing the MAS-J-HSQC approach. The photoCIDNP MAS-J-HSQC spectrum of the 5-ALA RC recorded with the pulse sequence shown in Fig. $2 \mathrm{~b}$ is presented in Fig. 5a. As in the case of photo-CIDNP MAS-J-HMQC, the spectrum is of high selectivity. The correlation peaks are grouped in the F2 dimension between 90 and $110 \mathrm{ppm}$, exactly the region of the feedback from protonated carbons C-5, C-10 and C-20. However, by closer inspection of the spectrum, it is possible to recognize that some peaks are missing, which on the other hand are present in the photo-CIDNP MAS-J-HMQC spectrum of 5-ALA RCs. The comparison of proton traces extracted from the F1 dimension for protonated C-5 (that also has a proximate ${ }^{13} \mathrm{C}$ label, C-4) and isolated $\mathrm{C}-20$ in both photo-CIDNP MAS-J-HMQC and photo-CIDNP MAS-J-HSQC experiments is presented in Fig. 5(b and c). Unlike the case for $\mathrm{u}^{13}{ }^{13} \mathrm{C}$ alanine, where we indeed observed the better performance of MAS-J-HSQC sequence over MAS-J-HMQC in terms of proton linewidths and signal intensity, the signal intensity from both protons $\mathrm{H}-5$ and $\mathrm{H}-20$ in 5-ALA sample is weaker in photo-CIDNP MAS-JHSQC. Also, there is no significant improvement of the linewidths: while being comparable for proton $\mathrm{H}-20$, the line for proton $\mathrm{H}-5$ is actually broader in case of photo-CIDNP MAS-J-HSQC.

Overall, regardless of the slightly poorer performance, the ${ }^{13} \mathrm{C}$ to- ${ }^{1} \mathrm{H}$ INEPT type of transfer of light-induced hyperpolarization in frozen protein was proven to be feasible and therefore could be used as a building block in the photo-CIDNP MAS-J-HSQC and other types of experiments. However, in the present study, photo-CIDNP MAS-J-HMQC proved to be more robust as it has fewer pulses and less sensitive to pulse imperfections, and therefore it was used throughout the work for signal assignments.

\subsection{Assignment of ${ }^{1} \mathrm{H}$ resonances in 5-, 4- and 3-ALA labeled RCs}

The expansions from the 2D photo-CIDNP MAS-J-HMQC spectra of 5-, 4- and 3-ALA R. sphaeroides WT are presented in Fig. 6(a-c, respectively). We start with the assignment of the signals from the 5-ALA RC sample. The assignment of ${ }^{13} \mathrm{C}$ signals of this labeling pattern was performed previously based on RFDR photo-CIDNP $[42,62]$ as well as 2D photo-CIDNP ${ }^{13} \mathrm{C}-{ }^{13} \mathrm{C}$ INADEQUATE [58]. In the 5-ALA pattern there are three protonated carbons: C-5, C-10 and $\mathrm{C}-20$. Given that three cofactors are responsible for generation of the solid-state photo-CIDNP effect, namely $\mathrm{P}_{\mathrm{L}}, \mathrm{P}_{\mathrm{M}}$ and $\Phi_{\mathrm{A}}$, we expect to find 9 correlation peaks in 2D photo-CIDNP 
a

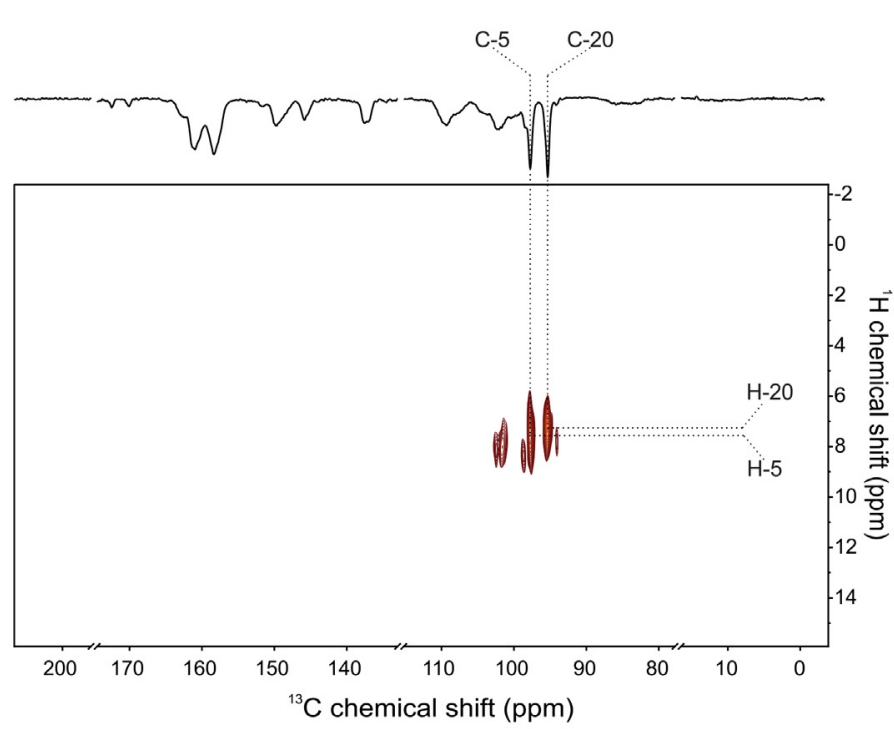

$\mathrm{H}-20$

-....... HMQC $\Delta=750 \mathrm{~Hz}$ HSQC $\triangle=690 \mathrm{~Hz}$

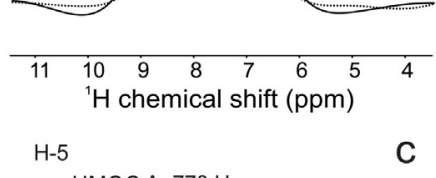

- HMQ $\triangle=770 \mathrm{~Hz}$

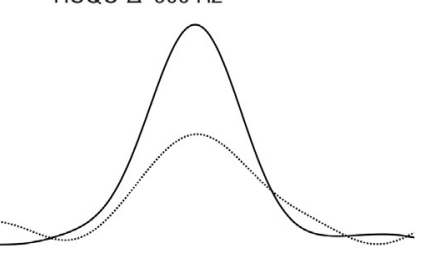

$\begin{array}{llllllll}11 & 10 & 9 & 8 & \dot{7} & 6 & 5 & 4 \\ & & \end{array}$

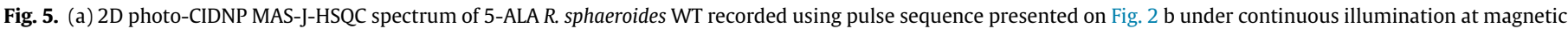

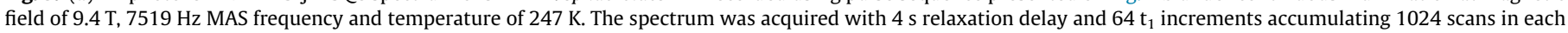

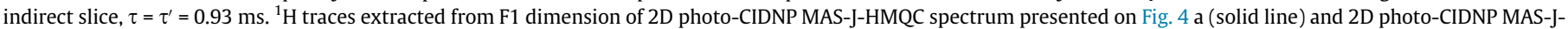
HSQC spectrum (dashed line) for position (b) 20 and (c) position 5 . The proton full linewidth at half maximum $\Delta$ is provided for each trace.

MAS-J-HMQC. Surprisingly, close examination of Fig. 6 a reveals at least 12 correlation peaks. The first ${ }^{13} \mathrm{C}$ peak is located at $94.1 \mathrm{ppm}$ and has correlation to a proton at $7.9 \mathrm{ppm}$. Interestingly, this peak was not observed in the previous works, presumably due to the low spectral dispersion and low intensity [42]. Nor this peak was observed in 2D photo-CIDNP ${ }^{13} \mathrm{C}-{ }^{13} \mathrm{C}$ INADEQUATE experiment, which suggests that it must be $\mathrm{C}-20$ as this is the only isolated ${ }^{13} \mathrm{C}$ label in 5-ALA pattern. Based on the signal intensity, we tentatively assign this correlation peak to $\mathrm{C}-20 / \mathrm{H}-20$ of $\Phi_{\mathrm{A}}$. The next intense ${ }^{13} \mathrm{C}$ peak is located at $95.3 \mathrm{ppm}$ and its correlated proton at $7.2 \mathrm{ppm}$. This must be the $\mathrm{C}-20 / \mathrm{H}-20$ correlation of $\mathrm{P}_{\mathrm{L}}$. Next is the ${ }^{13} \mathrm{C}$ peak at $97.6 \mathrm{ppm}$ with a proton at $7.3 \mathrm{ppm}$. The correlation peak is broad and asymmetric and might hide additional signals. Next group of peaks is rather weak and located between 98.4 and $99.5 \mathrm{ppm}$. The shoulder at $98.5 \mathrm{ppm}$ might be due to the response from C-5 of $\Phi_{\mathrm{A}}$, which was previously unresolved. The corresponding proton $\mathrm{H}-5$ is located at $7.2 \mathrm{ppm}$. The signals at 98.7 and 99.5 ppm must be then $\mathrm{C}-10$ of $\mathrm{P}_{\mathrm{L}}$ and $\mathrm{P}_{\mathrm{M}}$, respectively, with protons at 8.3 and $8.2 \mathrm{ppm}$. The additional signal at 99.5/6.4 ppm remains unclear. Proceeding further, the ${ }^{13} \mathrm{C}$ signal at $101.1 \mathrm{ppm}$ has a proton contact at $7.9 \mathrm{ppm}$ allowing for assignment to $\mathrm{C}-5 / \mathrm{H}-5$ of $\mathrm{P}_{\mathrm{M}} \cdot{ }^{13} \mathrm{C}$ at $101.5 \mathrm{ppm}$ with proton at $8.3 \mathrm{ppm}$ must be then $\mathrm{C}-10 / \mathrm{H}-10$ of $\Phi_{\mathrm{A}}$. Finally, solely $\mathrm{C}-20$ of $\mathrm{P}_{\mathrm{M}}$ is not assigned, and it might be the signal at $102.5 \mathrm{ppm}$ with the proton partner at $8.7 \mathrm{ppm}$. Two remaining ${ }^{13} \mathrm{C}$ peaks at 102.9 and $103.5 \mathrm{ppm}$ have protons at 7.2 and $7.4 \mathrm{ppm}$. Currently, we cannot assign them. We assume, that these additional peaks might rise from another cofactor. In fact, the labelling procedure with $\delta$ aminolevulinic acid results in the RCs in which all bacteriochlorophylls and bacteriopheophytins are labeled. This includes the accessory bacteriochlorophylls $B_{A}$ and $B_{B}$ (see Fig. S4). Previous studies also speculated on the presence of electron spin density at the accessory $B_{A}$ cofactor [38,42]. Time-resolved EPR [63] and optical studies [64] suggested involvement of $B_{A}$ as an intermediate in the electron transfer from the special pair to $\Phi_{A}$. However, the reported involvement of $B_{A}$ is too short-lived to generate the solid-state photo-CIDNP polarization on $\mathrm{B}_{\mathrm{A}}$, since this process is driven by the hyperfine interaction which needs to operate for at least tens of nanoseconds. On the other hand, we do not exclude the possibility that some unassigned signals might indeed originate from the accessory $\mathrm{BChl} a$ that might receive a part of lightinduced polarization due to the natural ${ }^{13} \mathrm{C}-{ }^{13} \mathrm{C}$ spin diffusion from the special pair. Indeed, in photo-CIDNP DARR experiments correlation peaks between ${ }^{13} \mathrm{C}$ positions located $>10 \AA$ apart are visible with $2 \mathrm{~s}$ mixing time [65]. Since accessory bacteriochlorophylls are located in close proximity to the special pair (distances $\mathrm{C}-10$ $\mathrm{P}_{\mathrm{M}} / \mathrm{C}-10 \mathrm{~B}_{\mathrm{A}} \sim 7 \AA$ and $\mathrm{C}-10 \mathrm{P}_{\mathrm{L}} / \mathrm{C}-10 \mathrm{~B}_{\mathrm{B}} \sim 8 \AA$ ), possible spin diffusion cannot be ruled out. Hence, the proton signals from 5-ALA $\mathrm{RC}$ are concentrated around $\sim 8 \mathrm{ppm}$, which is consistent with our previous observation [41], as well as with the chemical shifts obtained for monomer BChl $a$ in acetone-d6 [66]. At least 3 signals located at $99.5 / 6.4,102.9 / 7.2$ and $103.5 / 7.4 \mathrm{ppm}$ remain unassigned.

We now continue to assign the 4-ALA pattern shown in Fig. 6b. There are two $\mathrm{CH}$ groups with carbons $\mathrm{C}-8$ and $\mathrm{C}-17$ present in $\mathrm{P}_{\mathrm{L}}$, $\mathrm{P}_{\mathrm{M}}$ and $\Phi_{\mathrm{A}}$, therefore overall 6 correlation peaks are expected. Our starting point will be again the ${ }^{13} \mathrm{C}$ assignment in previous works $[38,67]$. The ${ }^{13} \mathrm{C}$ signal at $48.3 \mathrm{ppm}$ is correlated to a proton at $3.6 \mathrm{ppm}$, this must be $\mathrm{C}-17 / \mathrm{H}-17$ from $\mathrm{P}_{\mathrm{M}}$. Additional small peak located at $41.1 / 3.8 \mathrm{ppm}$ cannot be clearly assigned presently. The strong signal at $50.1 \mathrm{ppm}$ is correlated with peak at $4.6 \mathrm{ppm}$ and can be assigned to $\mathrm{C}-17 / \mathrm{H}-17$ from $\mathrm{P}_{\mathrm{L}}$. The correlation peak is asymmetric and therefore may contain additional signals that are not resolved. The ${ }^{13} \mathrm{C}$ signal at $51.4 \mathrm{ppm}$ can be attributed to $\mathrm{C}$ 17 of $\Phi_{\mathrm{A}}$, with corresponding proton $\mathrm{H}-7$ at $3.0 \mathrm{ppm}$. Next, there are two signals being close to each other, with positions at 53.1 and $53.4 \mathrm{ppm}$. Previously, only one carbon C-8 of $\mathrm{P}_{\mathrm{L}}$ was assigned for this position. We assume that signal at $53.4 \mathrm{ppm}$ is $\mathrm{C}-8$ of $\mathrm{P}_{\mathrm{L}}$ with its proton $\mathrm{H}-8$ at $3.9 \mathrm{ppm}$. Then, the second peak at $53.1 / 3.1 \mathrm{ppm}$ remains unassigned. The signal at $54.9 \mathrm{ppm}$ must originate from C-8 of $\Phi_{\mathrm{A}}$, and has correlated proton at $4.3 \mathrm{ppm}$. As the correlation pattern suggests, there seems to be at least 


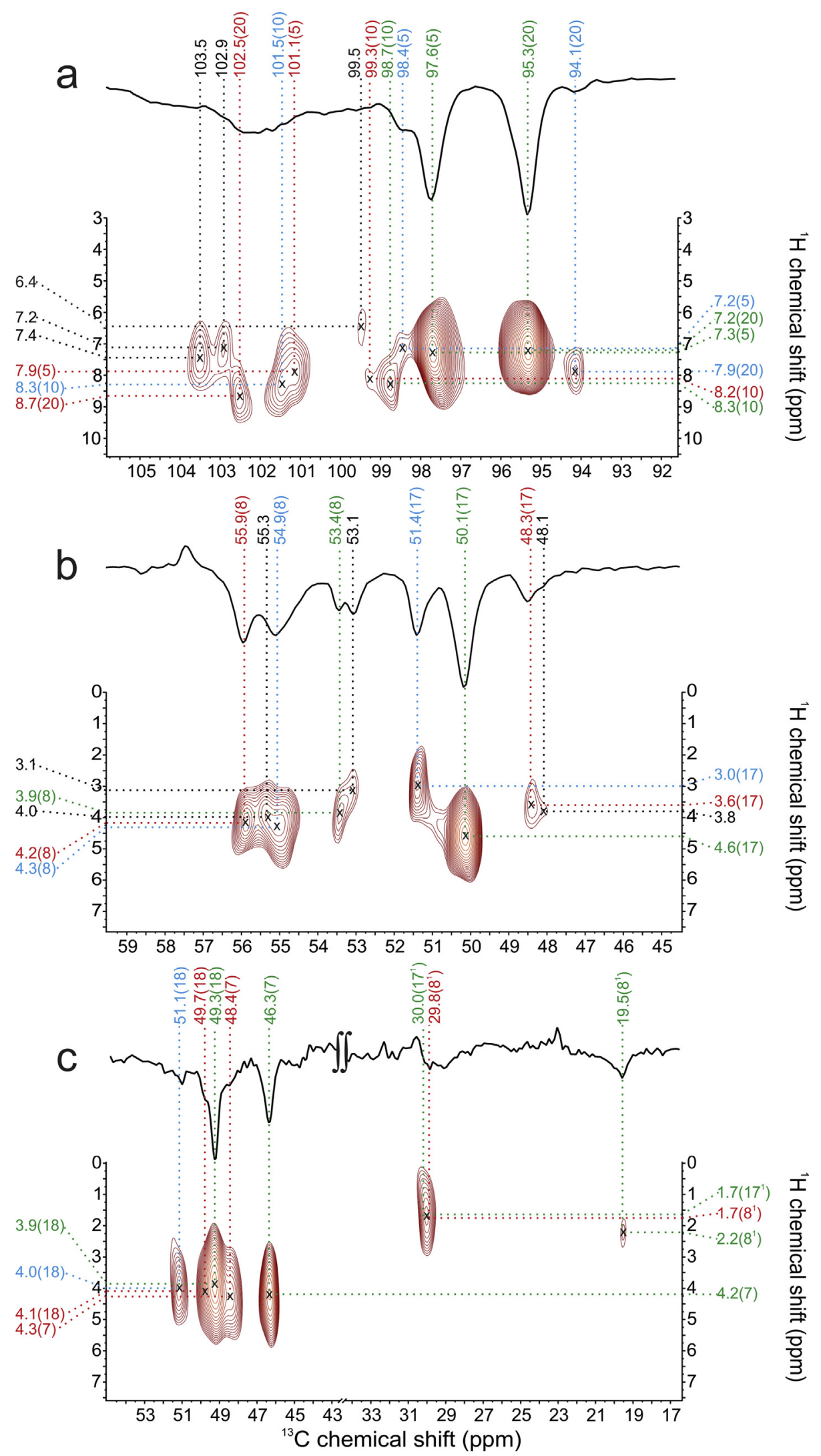

Fig. 6. The expansions from 2D photo-CIDNP MAS-J-HMQC spectra of (a) 5-ALA (b) 4-ALA and (c) 3-ALA R. sphaeroides WT with assignments of ${ }^{13} \mathrm{C}-{ }^{1} \mathrm{H}$ correlation peaks. The color code refers to the assignment of the three cofactors forming the spin correlated radical pair: green, red and blue refer to two BChl $a$ molecules of the donor $\left(\mathrm{P}_{\mathrm{L}}\right.$ and $\left.\mathrm{P}_{\mathrm{M}}\right)$ and the acceptor BPhe $a\left(\Phi_{\mathrm{A}}\right)$, respectively. (For interpretation of the references to color in this figure legend, the reader is referred to the web version of this article.) 
one more peak, located at $\sim 55.3 / 4.0 \mathrm{ppm}$, which remains unassigned. Finally, the signal at $55.9 \mathrm{ppm}$ must be $\mathrm{C}-8$ of $\mathrm{P}_{\mathrm{M}}$, which has corresponding proton $\mathrm{H}-8$ at $4.2 \mathrm{ppm}$. In total, we were able to locate at least 9 signals.

Thus, the $\mathrm{H}-17$ chemical shifts range from 3 to $4.5 \mathrm{ppm}$, while the $\mathrm{H}-8$ are grouped between 3.1 and $4.3 \mathrm{ppm}$. This matches rather well with our previous assumption that $\mathrm{H}-8$ and $\mathrm{H}-17$ resonate around 3.7 and $4.4 \mathrm{ppm}$, respectively [41]. As in the case with 5ALA, we spotted three more correlation peaks than expected, at 48.1/3.8, 53.1/3.1 and 55.3/4.0 ppm.

Finally, we discuss the assignment of the signals form the 3-ALA RC sample. Also this assignment can be based on the ${ }^{13} \mathrm{C}$ resonances identified in previous works $[65,68]$. The first ${ }^{13} \mathrm{C}$ peak is located at $19.5 \mathrm{ppm}$ with its proton signal at $2.2 \mathrm{ppm}$. Preliminary 2D INADEQUATE data (not shown) suggest that signal at $19.5 \mathrm{ppm}$ might originate from $\mathrm{C}-8{ }^{1}$ of $\mathrm{P}_{\mathrm{L}}$. Then, the ${ }^{13} \mathrm{C}$ at $29.8 \mathrm{ppm}$ could be $\mathrm{C}-8^{1}$ of $\mathrm{P}_{\mathrm{M}}$ with its proton $\mathrm{H}-8^{1}$ at $1.7 \mathrm{ppm}$. Such assignment suggests the difference of about $10 \mathrm{ppm}$ in ${ }^{13} \mathrm{C}$ chemical shifts between $C-8^{1}$ of $P_{L}$ and $P_{M}$, and requires further investigation. On the other hand, it was previously reported that the position C-12 (quaternary and therefore not visible in this work) has a difference of $9.3 \mathrm{ppm}$ between $\mathrm{P}_{\mathrm{L}}$ and $\mathrm{P}_{\mathrm{M}}$, and therefore makes the above statement probable. The very close peak at $30.0 \mathrm{ppm}$ could as well originate from $\mathrm{C}-17^{1}$ of $\mathrm{P}_{\mathrm{L}}$ with its proton $\mathrm{H}-8^{1}$ at $1.7 \mathrm{ppm}$. Both positions $\mathrm{C}-8^{1}$ and $\mathrm{C}-17^{1}$ are the $\mathrm{CH}_{2}$ groups, which were still possible to observe despite that the $\tau$ delay was optimized to gain maximum intensity from the $\mathrm{CH}$ groups. Next, the ${ }^{13} \mathrm{C}$ peak at $46.3 \mathrm{ppm}$ must be $\mathrm{C}-7$ of $\mathrm{P}_{\mathrm{L}}$ with its correlated proton $\mathrm{H}-7$ at $4.2 \mathrm{ppm}$. Then, the signal at $48.4 \mathrm{ppm}$ with proton at $4.3 \mathrm{ppm}$ might be $\mathrm{C}-7 / \mathrm{H}-7$ of $\mathrm{P}_{\mathrm{M}}$. We assign the peak at $49.3 \mathrm{ppm}$ with correlated proton at $3.9 \mathrm{ppm}$ to $\mathrm{C}-18 / \mathrm{H}-18$ of $\mathrm{P}_{\mathrm{L}}$. This correlation peak is rather broad and might contain yet another signal at 49.7/4.1 ppm. This could be the $\mathrm{C}-18 / \mathrm{H}-18$ response from $\mathrm{P}_{\mathrm{M}}$. Finally, the ${ }^{13} \mathrm{C}$ signal at $51.1 \mathrm{ppm}$ might be $\mathrm{C}-18$ of $\Phi_{\mathrm{A}}$ with its proton at $4.0 \mathrm{ppm}$.

Previously, we assumed that protons $\mathrm{H}-17^{1}$ and $\mathrm{H}-8^{1}$ resonate between 1.1 and $2.5 \mathrm{ppm}$, while $\mathrm{H}-18$ and $\mathrm{H}-7$ around 4 and $3 \mathrm{ppm}$. This is in agreement with ref [41]. We expect that the upcoming 2D photo-CIDNP ${ }^{13} \mathrm{C}-{ }^{13} \mathrm{C}$ INADEQUATE experiments on 3- and 4-ALA labeled RCs in analogy to ref [58] will allow for an improvement of the existing assignments of ${ }^{13} \mathrm{C}$ signals which also might allow for rationalizing the unassigned ${ }^{1} \mathrm{H}$ correlations.

The full assignment of ${ }^{1} \mathrm{H}$ chemical shifts of $\mathrm{P}_{\mathrm{L}}, \mathrm{P}_{\mathrm{M}}$ and $\Phi_{\mathrm{A}}$ is presented in Tables 1,2 and 3, respectively. To support our experimental data, we performed the DFT calculation of ${ }^{1} \mathrm{H}$ chemical shifts based on several models of the special pair. The details about the calculation procedure as well as the models used can be found in Supporting information. The obtained theoretical chemical shifts match rather well the experimental data. Thus, for protons $\mathrm{H}-8$, $\mathrm{H}-17, \mathrm{H}-18$ of both $\mathrm{P}_{\mathrm{L}}$ and $\mathrm{P}_{\mathrm{M}}$ and also $\mathrm{H}-10$ and $\mathrm{H}-20$ of $\mathrm{P}_{\mathrm{M}}$ the discrepancy between experimental and theoretical chemical shifts is $\leq 0.5 \mathrm{ppm}$, while for protons $\mathrm{H}-7, \mathrm{H}-17^{1}$ of both $\mathrm{P}_{\mathrm{L}}$ and $\mathrm{P}_{\mathrm{M}}$, and $\mathrm{H}-5, \mathrm{H}-10$ of $\mathrm{P}_{\mathrm{L}}$ this discrepancy is $<1 \mathrm{ppm}$. Considering the error of the experimentally obtained chemical shifts which is estimated to be at least $\pm 0.5 \mathrm{ppm}$ due to the linewidths and the need to use the external referencing of ${ }^{1} \mathrm{H}$ ppm scale, we consider the agreement between calculated and experimental shifts as good, which supports the suggested assignment. The biggest discrepancy between experimental and predicted proton chemical shift of $1.9 \mathrm{ppm}$ is observed for $\mathrm{H}-20$ of $\mathrm{P}_{\mathrm{L}}$, for which we do not have an explanation at the current moment. We do not exclude, however, that such discrepancy might be due to the presence of two phenylalanine residues Phe-L180 and Phe-L181 in the proximity to C-20, which were not accounted in the calculation models. The aromatic rings of these residues generate ring currents [69] that might affect the chemical shift of $\mathrm{H}-20$.

We estimated the ${ }^{1} \mathrm{H}$ ring current shifts generated by two BChl $a$ of special pair on each other, and corrected the experimental chemical shifts respectively [39]. In this way, we attempted to compare the proton chemical shifts of BChl $a$ and BPhe $a$ in the native protein pocket with the isolated molecules in solution. The previous ${ }^{13} \mathrm{C}$ photo-CIDNP MAS NMR studies showed the asymmetry in distribution of the electron spin density in the electronic ground state of the special pair in favor of the $P_{L}$ cofactor [39]. Such symmetry break was attributed to the internal factors such as conformation of the special pair rather than the influence from the external protein surrounding. In particular, the symmetry break has been shown to be controlled by the intrinsic nonaromatic substituents [65]. Thus, the side-chain carbons of $P_{L}$ showed mainly the up-field shifts as compared to the ${ }^{13} \mathrm{C}$ shifts obtained in solution. For the side-chain carbons of $\mathrm{P}_{\mathrm{M}}$, on the other hand, mainly the downfield shift was observed. It was concluded that different folding of aliphatic side-chains has an effect on attached aromatic system. While the aromatic system of $\mathrm{P}_{\mathrm{L}}$ receives electron density from its periphery, the electron density of the aromatic ring of $\mathrm{P}_{\mathrm{M}}$ is decreased. In this way, the aliphatic periphery can stabilize the charge distribution in the excited state, in which the electron charge is mainly localized on $\mathrm{P}_{\mathrm{M}}$. The described effects are relatively week and result in only minor deviation of the ${ }^{13} \mathrm{C}$ chemical shifts between the special pair and

\section{Table 1}

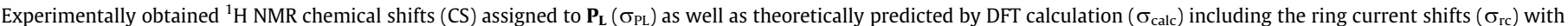

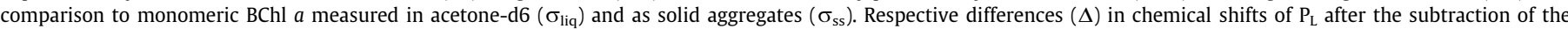
estimated ring currents $\left(\sigma_{\text {cor }}\right)$ and chemical shifts obtained in acetone-d6.

\begin{tabular}{|c|c|c|c|c|c|c|c|}
\hline \multirow[t]{3}{*}{ Atom № } & \multicolumn{7}{|c|}{${ }^{1} \mathrm{H}$ chemical shift, ppm } \\
\hline & \multicolumn{2}{|c|}{$\begin{array}{l}\text { CS }(\mathrm{BChl} a) \\
\text { literature }^{\mathrm{a}}\end{array}$} & \multirow[t]{2}{*}{$\begin{array}{l}\mathrm{CS}\left(\mathrm{P}_{\mathrm{L}}\right) \text { this } \\
\text { work }\left(\sigma_{\mathrm{PL}}\right)^{\mathrm{b}}\end{array}$} & \multirow[t]{2}{*}{$\begin{array}{l}\text { Ring current } \\
\text { shift }\left(\sigma_{\mathrm{rc}}\right)^{\mathrm{c}}\end{array}$} & \multirow[t]{2}{*}{$\begin{array}{l}\text { Corrected CS } \\
\left(\sigma_{\text {cor }}=\sigma_{\mathrm{PL}}-\sigma_{\mathrm{rc}}\right)\end{array}$} & \multirow[t]{2}{*}{ Calculated $\left(\sigma_{\text {calc }}\right)^{\mathrm{c}}$} & \multirow[t]{2}{*}{$\begin{array}{l}\text { Difference } \\
\Delta=\left(\sigma_{\text {cor }}-\sigma_{\text {liq }}\right)\end{array}$} \\
\hline & $\sigma_{\text {liq }}$ & $\sigma_{\mathrm{ss}}$ & & & & & \\
\hline 5 & 8.81 & 6.75 & 7.3 & -2.6 & 9.9 & 6.6 & 1.1 \\
\hline 10 & 8.40 & 5.50 & 8.3 & 0.1 & 8.2 & 7.6 & -0.2 \\
\hline 20 & 8.36 & 5.89 & 7.2 & 0.1 & 7.1 & 9.1 & -1.3 \\
\hline 7 & 4.24 & 3.06 & 4.2 & -0.1 & 4.3 & 5.1 & 0.1 \\
\hline 8 & 4.03 & 2.17 & 3.9 & -0.2 & 4.1 & 4.1 & 0.1 \\
\hline 17 & 3.92 & 2.45 & 4.6 & 0.2 & 4.4 & 4.4 & 0.5 \\
\hline 18 & 4.32 & 2.45 & 3.9 & 0.3 & 3.6 & 3.8 & -0.7 \\
\hline $8^{1}$ & 2.08 & 0.96 & 2.2 & 0.6 & 1.6 & 2.6 & -0.5 \\
\hline $17^{1}$ & 2.37 & 0.96 & 1.7 & 0.4 & 1.3 & 2.5 & -1.1 \\
\hline
\end{tabular}

${ }^{\text {a }}$ Data according to [66] obtained from $\left[\mathrm{u}-{ }^{13} \mathrm{C}-{ }^{15} \mathrm{~N}\right] \mathrm{BChl} a$ in acetone-d6 $\left(\sigma_{\text {liq }}\right)$ and solid aggregates $\left(\sigma_{\mathrm{ss}}\right)$.

b The estimated error is about $\pm 0.5 \mathrm{ppm}$.

c Based on model M (Fig. S3a and Supplementary Table S1). 
Table 2

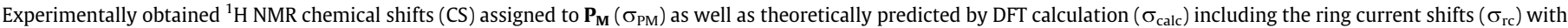

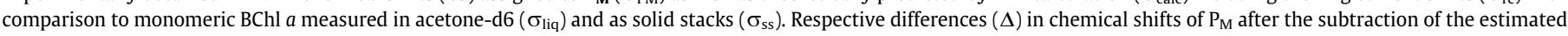
ring currents $\left(\sigma_{\text {cor }}\right)$ and chemical shifts obtained in acetone-d6.

\begin{tabular}{|c|c|c|c|c|c|c|c|}
\hline \multirow[t]{3}{*}{ Atom № } & \multicolumn{7}{|c|}{${ }^{1} \mathrm{H}$ chemical shift, ppm } \\
\hline & \multicolumn{2}{|c|}{$\begin{array}{l}\mathrm{CS}(\mathrm{BChl} a) \\
\text { literature }^{\mathrm{a}}\end{array}$} & \multirow[t]{2}{*}{$\begin{array}{l}\operatorname{CS}\left(P_{M}\right) \text { this } \\
\text { work }\left(\sigma_{\mathrm{PM}}\right)^{\mathrm{b}}\end{array}$} & \multirow[t]{2}{*}{$\begin{array}{l}\text { Ring current } \\
\operatorname{shift}\left(\sigma_{\mathrm{rc}}\right)^{\mathrm{c}}\end{array}$} & \multirow[t]{2}{*}{$\begin{array}{l}\text { Corrected } \\
\operatorname{CS}\left(\sigma_{\text {cor }}=\sigma_{\mathrm{PM}}-\sigma_{\mathrm{rc}}\right)\end{array}$} & \multirow[t]{2}{*}{ Calculated $\left(\sigma_{\text {calc }}\right)^{\mathrm{c}}$} & \multirow[t]{2}{*}{$\begin{array}{l}\text { Difference } \\
\Delta=\left(\sigma_{\text {cor }}-\sigma_{\text {liq }}\right)\end{array}$} \\
\hline & $\sigma_{\text {liq }}$ & $\sigma_{\mathrm{ss}}$ & & & & & \\
\hline 5 & 8.81 & 6.75 & 7.9 & -1.4 & 9.3 & 7.3 & 0.5 \\
\hline 10 & 8.40 & 5.50 & 8.2 & 0.3 & 7.9 & 8.3 & -0.5 \\
\hline 20 & 8.36 & 5.89 & 8.7 & -0.6 & 9.3 & 8.2 & 0.9 \\
\hline 7 & 4.24 & 3.06 & 4.3 & 0.4 & 3.9 & 5.1 & -0.3 \\
\hline 8 & 4.03 & 2.17 & 4.2 & 0.1 & 4.1 & 4.5 & 0.1 \\
\hline 17 & 3.92 & 2.45 & 3.6 & 0.0 & 3.6 & 4.1 & -0.3 \\
\hline 18 & 4.32 & 2.45 & 4.0 & 0.2 & 3.8 & 3.5 & -0.5 \\
\hline $8^{1}$ & 2.08 & 0.96 & 1.7 & 0.7 & 1.0 & 2.5 & -1.0 \\
\hline $17^{1}$ & 2.37 & 0.96 & - & 0.4 & - & 3.1 & - \\
\hline
\end{tabular}

${ }^{\mathrm{a}}$ Data according to [66] obtained from $\left[\mathrm{u}-{ }^{13} \mathrm{C}-{ }^{15} \mathrm{~N}\right] \mathrm{BChl} a$ in acetone-d6 $\left(\sigma_{\text {liq }}\right)$ and solid aggregates $\left(\sigma_{\mathrm{ss}}\right)$.

b The estimated error is about $\pm 0.5 \mathrm{ppm}$.

c Based on model M (Fig. S3a and Supplementary Table S1).

Table 3

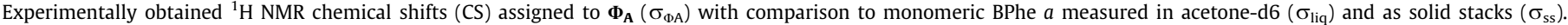
Respective differences $(\Delta)$ in chemical shifts.

\begin{tabular}{|c|c|c|c|c|}
\hline \multirow[t]{3}{*}{ Atom № } & \multicolumn{4}{|c|}{${ }^{1} \mathrm{H}$ chemical shift, ppm } \\
\hline & \multicolumn{2}{|c|}{ CS (BPhe $a$ ) literature ${ }^{a}$} & \multirow[t]{2}{*}{$\operatorname{CS}\left(\Phi_{\mathrm{A}}\right)$ this work $\left(\sigma_{\Phi \mathrm{A}}\right)^{\mathrm{b}}$} & \multirow[t]{2}{*}{ Difference $\Delta=\left(\sigma_{\Phi A}-\sigma_{\text {liq }}\right)^{c}$} \\
\hline & $\sigma_{\text {liq }}$ & $\sigma_{\mathrm{ss}}$ & & \\
\hline 5 & 9.05 & 7.04 & 7.2 & -1.8 \\
\hline 10 & 8.66 & 5.10 & 8.3 & -0.4 \\
\hline 20 & 8.73 & 5.80 & 7.9 & -0.8 \\
\hline 7 & 4.35 & 2.73 & - & - \\
\hline 8 & 4.07 & 2.22 & 4.3 & 0.2 \\
\hline 17 & 3.99 & 2.73 & 3.0 & -1.0 \\
\hline 18 & 4.41 & 2.45 & - & - \\
\hline $8^{1}$ & 2.07 & 1.2 & - & - \\
\hline $17^{1}$ & 2.4 & - & - & - \\
\hline
\end{tabular}

a Data according to [66] obtained from $\left[\mathrm{u}-{ }^{13} \mathrm{C}-{ }^{15} \mathrm{~N}\right]$ BPhe $a$ in acetone-d6 $\left(\sigma_{\text {liq }}\right)$ and solid aggregates $\left(\sigma_{\mathrm{ss}}\right)$.

b The estimated error is about $\pm 0.5 \mathrm{ppm}$.

monomeric cofactor in solution [65]. It is expected that the protons are less sensitive to such differences in local electron spin density. Indeed, for atoms with p-orbitals, such as carbon, the paramagnetic contribution to the nuclear chemical shift is usually the dominant term. Thus, an increased electron density at the carbons causes electronic repulsion and expansion of bonding orbitals, which in turn increases the distance of the $2 p$ electron density from the nucleus. As a result, the chemical shift moves up-field due to reduced paramagnetic shielding. For proton, on the other hand, that has only one s-electron, the diamagnetic shielding effect is the dominant. Thus, provided that all contributions to proton chemical shift, such as ring currents, charge effects, magnetic anisotropy etc. remain constant, solely the variation of electron density on p-orbitals of adjacent carbon neighbors should not affect the proton chemical shifts. Indeed, it appears that the differences between the majority of the observed chemical shifts of the special pair are $\leq 1 \mathrm{ppm}$ as compared to the monomeric BChl $a$ (see $\Delta$ in Tables 1-3). Such small differences are already at the border of the error in determining the ${ }^{1} \mathrm{H}$ chemical shifts in solid-state NMR. In the present study, we are limited to the proton positions $5,10,20,7,8,17,18,8^{1}$ and $17^{1}$ due to the specificity of the ${ }^{13} \mathrm{C}$ labeling procedure, thus the periphery is represented by positions $7,8,17,18,8^{1}$ and $17^{1}$, for which the disturbance of ${ }^{13} \mathrm{C}$ chemical shifts did not exceed $3-4 \mathrm{ppm}$ [65], thus the effect on ${ }^{1} \mathrm{H}$ is expected to be negligible. Moreover, even at the position $8^{1}$, reassigned in this work, for which the experimental ${ }^{13} \mathrm{C}$ chemical shifts between $\mathrm{P}_{\mathrm{L}}$ and $\mathrm{P}_{\mathrm{M}}$ differ by $10 \mathrm{ppm}, \mathrm{H}-8^{1} \mathrm{P}_{\mathrm{L}}$ and $\mathrm{P}_{\mathrm{M}}$ differ by only
$0.5 \mathrm{ppm}$. The only significant difference between $\mathrm{P}_{\mathrm{L}}$ and $\mathrm{P}_{\mathrm{M}}$ was spotted for position $\mathrm{H}-20$, for which we do not have explanation at this moment.

While we expect that the rest of protons that were not observed in the present work should not be disturbed and significantly differ between two halves of the special pair, more data on ${ }^{1} \mathrm{H}$ chemical shifts from positions $2^{1}, 3^{2}, 8^{2}, 12^{1}, 17^{2}$ from the periphery of the cofactors would be needed to make a final conclusion. For that, the photo-CIDNP MAS-J-HMQC experiment on uniformly labeled u-ALA RC [68] will have to be recorded.

\subsection{Comparison of "dark" and "light" HETCOR on 5-ALA R. sphaeroides WT}

Finally, to compare the performance of photo-CIDNP MAS-JHMQC and classical CP HETCOR sequence, we recorded the CP HETCOR spectrum of 5-ALA R. sphaeroides WT in the magnetic field of $20 \mathrm{~T}$ in the dark. As was mentioned before, the isotopic labeling procedure with the use of ALA results in the RCs in which all BChls and BPhes are labeled, that include accessory bacteriochlorophylls $\mathrm{B}_{\mathrm{A}}$ and $\mathrm{B}_{\mathrm{B}}$, the $\mathrm{CP}$ HETCOR obtained in the dark could aid the identification of unassigned peaks discussed above.

The corresponding spectrum of 5-ALA $R$. sphaeroides WT is presented on Fig. 7a. The multiple ${ }^{13} \mathrm{C}$ signals between 10 and $70 \mathrm{ppm}$ are the responses from the saturated carbons of the protein as well as the signal from the detergent, with the correlated proton resonance between -1 and $4 \mathrm{ppm}$. The ${ }^{13} \mathrm{C}$ signals around $120 \mathrm{ppm}$ 

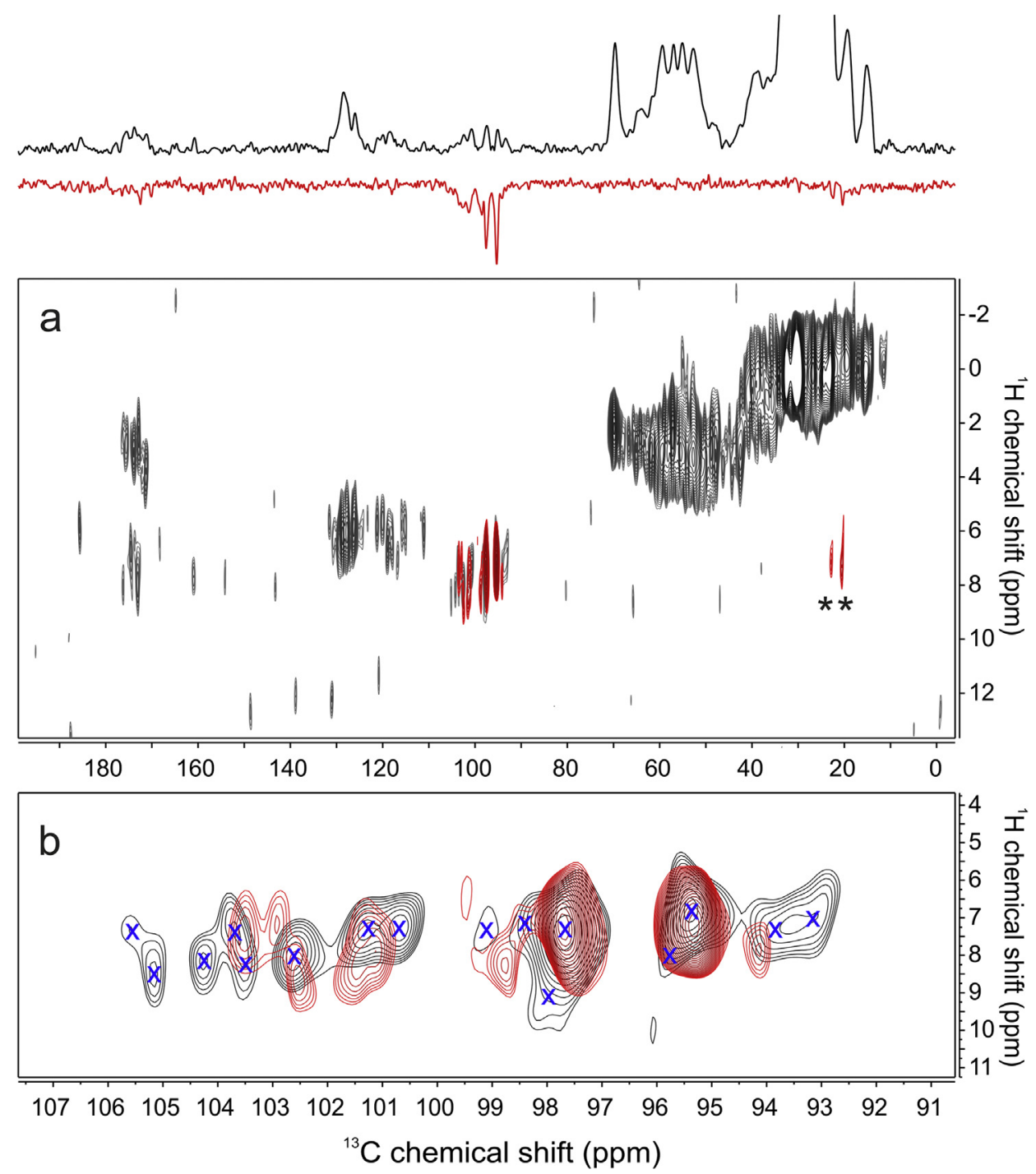

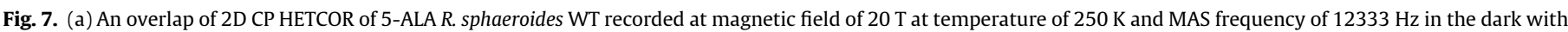

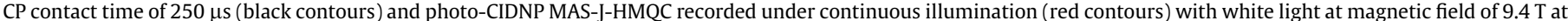

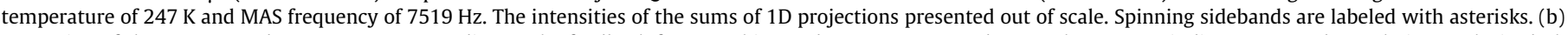

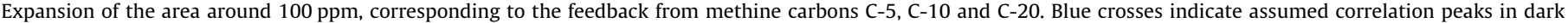
spectrum. (For interpretation of the references to color in this figure legend, the reader is referred to the web version of this article.)

are due to the aromatic residues of the protein, with corresponding aromatic protons resonating around $7 \mathrm{ppm}$. The strong signal around $175 \mathrm{ppm}$ is a cumulative signal from the amide carbonyls in the protein, with respective correlations to $\mathrm{H}_{\alpha}$ at $\sim 4 \mathrm{ppm}$ to the backbone amide protons at $\sim 8 \mathrm{ppm}$. Finally, weak ${ }^{13} \mathrm{C}$ signals between 92 and $106 \mathrm{ppm}$ are the responses from the methine carbons of BChl $a$ and BPhe $a$ cofactors, namely the labeled position C$5, \mathrm{C}-10$ and $\mathrm{C}-20$, with the corresponding protons that resonate at around $8 \mathrm{ppm}$. The overlap of "dark" CP-based HETCOR and "light" photo-CIDNP MAS-J-HMQC demonstrates advantage of the latter approach due to high selectivity of obtained spectra: while classical CP HETCOR approach contains NMR feedback from 6 almost identical cofactors, the solid-state photo-CIDNP effect is generated exclusively on the cofactors that form the SCRP. Moreover, the selective signal enhancement ensures the absence of the strong signals belonging to the protein side chains, which would otherwise overlap with the ${ }^{13} \mathrm{C}$ and ${ }^{1} \mathrm{H}$ signals of labeled $\mathrm{BChl} a$ and BPhe $a$, especially in the case of 4-ALA and 3-ALA labeled RCs with their carbon resonances between 20 and $50 \mathrm{ppm}$ and proton between 1 and 5 ppm.
Close examination of the spectral region around $100 \mathrm{ppm}$ (Fig. 7b) allows to locate at least 16 signals out of 18 expected, generated by ${ }^{13} C$ labels at positions $C-5, C-10$ and $C-20$ of $P_{L}, P_{M}, \Phi_{A}, \Phi_{B}$, $\mathrm{B}_{\mathrm{A}}$ and $\mathrm{B}_{\mathrm{B}}$. The general trend in the positions of ${ }^{1} \mathrm{H}$ signals in light and dark experiments seems to hold within the experimental error. In particular, correlation signals previously assigned to $\mathrm{C}-5 / \mathrm{H}-5$ and $\mathrm{C}-20 / \mathrm{H}-20$ of $\mathrm{P}_{\mathrm{L}}, \mathrm{P}_{\mathrm{M}}$ and $\Phi_{\mathrm{A}}$ match very well in both experiments, which allows for assuming that there are no evident light-induced changes in the close electronic environment around these positions. This would match with previous ${ }^{13} \mathrm{C}$ RFDR NMR experiments that did not show light-induced changes on the ${ }^{13} \mathrm{C}$ chemical without and with illumination, thus suggesting that electronic structure around the labeled ${ }^{13} \mathrm{C}$ atoms is not altered by illumination, and therefore the protein does not undergo noticeable structural changes during the photoreaction $[38,42]$.

Comparison of the two spectra reveals that unassigned signal at 103.5/7.4 ppm from the light-induced 5-ALA spectrum has a clear partner on the dark spectrum at $103.7 / 7.4 \mathrm{ppm}$; the signal at $102.9 / 7.2 \mathrm{ppm}$ could be a part of a $102.6 / 7.9 \mathrm{ppm}$; finally, the peak at 99.5/6.4 ppm could be either a part of the proximate correlation 
at 99.1/7.0 or one of the missing peaks due to weak intensity. Overall, such tentative comparison does not rule out the possibility that the unassigned signals present on light-induced spectra might originate from one of the labeled cofactors that does not participate in the evolution of SCRP and receives part of the polarization due to the spin diffusion. Experiments at high MAS frequency are expected to alter efficiency of spin diffusion and therefore might help resolving this assumption. In future, precise ${ }^{13} \mathrm{C}$ assignment of dark spectrum will be carried out based on high-resolution 2D ${ }^{13} \mathrm{C}-{ }^{13} \mathrm{C}$ homonuclear correlation experiments. We expect that the accessory BChls could be potentially discriminated from the special pair as the chemical shifts of accessory $B_{A}$ and $B_{B}$ are less influenced by the ring current effects as compared to $\mathrm{P}_{\mathrm{L}}$ and $\mathrm{P}_{\mathrm{M}}$ located only $\sim 3.4 \AA$ apart. Moreover, the ${ }^{13} \mathrm{C}$ chemicals shifts of accessory BChls are not expected to be disturbed by the symmetry break and therefore should be more comparable to the ${ }^{13} \mathrm{C}$ chemical shifts of monomeric BChl $a$ in solution. The discussion on the origin of unresolved signals observed in labeled RCs will be continued in our upcoming work.

\section{Conclusions}

In the present study, we demonstrated the feasibility of the transfer of light-induced hyperpolarization occurring on selective ${ }^{13} \mathrm{C}$ nuclei of photosynthetic cofactors to covalently bonded protons via J-coupling in the form of heteronuclear solid-state photo-CIDNP experiments, both MQ and SQ based. The photoCIDNP MAS-J-HMQC experiment was proven to be robust and efficient for mapping the proton chemical shifts of the electron donor-acceptor pairs in selectively ${ }^{13} \mathrm{C}$-labeled RCs of $R$. sphaeroides WT. We were able to resolve chemical shifts from all protons covalently bound to ${ }^{13} \mathrm{C}$ labels of active cofactors in 3-, 4- and 5-ALA labeled RCs. Additionally, more correlation peaks in 5- and 4-ALA patterns were spotted and attributed to the feedback from a third labeled molecule, presumably accessory bacteriochlorophyll $a$ that does not participate in the evolution of SCRP and receives the nuclear spin polarization from the special pair due to the natural spin diffusion. The clear advantage of this approach as opposed to the classical CP HETCOR is the selectivity of obtained spectra. Thus, the signals arising exclusively from the cofactors participating in the electron transfer chain are detected, which greatly simplifies the assignment. In particular, the assignment of 3-, 4-ALA patterns, whose ${ }^{13} \mathrm{C}$ and ${ }^{1} \mathrm{H}$ chemical shift are located in the aliphatic region, was possible.

The obtained map of proton chemical shifts map will be used to discriminate between intra- and intermolecular transfers of lightinduced hyperpolarization in heteronuclear spin-torch experiments [41] and to locate the potential transfers into the protein pocket of the RCs from $R$. sphaeroides WT. While the solid-state photo-CIDNP effect has been observed in all natural photosynthetic RC studied so far, thus providing the source of the photo-induced polarization, the photo-CIDNP MAS-J-HMQC experiment can potentially offer fast access to the maps of proton chemical shifts in other RCs, including plant's photosystem II.

\section{Acknowledgments}

Generous support by the Deutsche Forschungsgemeinschaft, Germany, is acknowledged (MA-4972/2-1). PB and JM would like to thank Prof. Clemens Glaubitz and Dr. Johanna Becker-Baldus (Goethe-University Frankfurt) for providing the access to $850 \mathrm{MHz}$ NMR spectrometer and technical assistance. PB would like to thank Prof. Shimon Vega (Weizmann Institute of Science) for exciting discussions. KRM would like to acknowledge
Department of Science and Technology, India, for support under the INSPIRE Faculty Scheme, IFA-CH-150.

\section{Appendix A. Supplementary material}

Supplementary data associated with this article can be found, in the online version, at https://doi.org/10.1016/j.jmr.2018.11.013.

\section{References}

[1] A.A. Maudsley, R.R. Ernst, Indirect detection of magnetic resonance by heteronuclear two-dimensional spectroscopy, Chem. Phys. Lett. 50 (1977) 368-372.

[2] P. Caravatti, G. Bodenhausen, R.R. Ernst, Heteronuclear solid-state correlation spectroscopy, Chem. Phys. Lett. 89 (1982) 363-367.

[3] J.E. Roberts, S. Vega, R.G. Griffin, Two-dimensional heteronuclear chemical shift correlation spectroscopy in rotating solids, J. Am. Chem. Soc. 106 (1984) 2506-2512.

[4] Z. Gu, C.F. Ridenour, C.E. Bronnimann, T. Iwashita, A. McDermott, Hydrogen bonding and distance studies of amino acids and peptides using solid state 2D ${ }^{1} \mathrm{H}-{ }^{13} \mathrm{C}$ heteronuclear correlation spectra, J. Am. Chem. Soc. 118 (1996) 822829.

[5] S. Li, Y. Su, W. Luo, M. Hong, Water-protein interactions of an arginine-rich membrane peptide in lipid bilayers investigated by solid-state NMR spectroscopy, J. Phys. Chem. B 114 (2011) 4063-4069.

[6] R. Fu, E.D. Gordon, D.J. Hibbard, M. Cotton, High resolution heteronuclear correlation NMR spectroscopy of an antimicrobial peptide in aligned lipid bilayers: peptide-water interactions at the water-bilayer interface, J. Am. Chem. Soc. 131 (2009) 10830-10831.

[7] C. Song, C. Lang, J. Mailliet, J. Hughes, W. Gärtner, J. Matysik, Exploring chromophore-binding pocket: high-resolution solid-state $1 \mathrm{H}-13 \mathrm{C}$ interfacial correlation NMR spectra with windowed PMLG scheme, Appl. Magn. Reson. 42 (2012) 79-88.

[8] C. Song, M. Mroginski, C. Lang, J. Kopycki, W. Gärtner, J. Matysik, J. Hughes, 3D structures of plant phytochrome $\mathrm{A}$ as $\mathrm{Pr}$ and $\mathrm{Pfr}$ from solid-state NMR: implication for molecular function, Front. Plant. Sci. 9 (2018) 498.

[9] A. Alia, J. Matysik, I. de Boer, P. Gast, H.J. van Gorkom, H.J.M. de Groot, Heteronuclear 2D $\left({ }^{1} \mathrm{H}-{ }^{13} \mathrm{C}\right)$ MAS NMR resolves the electronic structure of coordinated histidines in light-harvesting complex II: assessment of charge transfer and electronic delocalization effect, J. Biomol. NMR 28 (2004) 157164.

[10] A. Alia, P.K. Wawrzyniak, G.J. Janssen, F. Buda, J. Matysik, H.J.M. de Groot, Differential charge polarization of axial histidines in bacterial reaction centers balances the asymmetry of the special pair, J. Am. Chem. Soc. 131 (2009) 9626-9627.

[11] G.A. Morris, R. Freeman, Enhancement of nuclear magnetic resonance signals by polarization transfer, J. Am. Chem. Soc. 101 (1979) 760-762.

[12] B.J. van Rossum, E.A. Schulten, J. Raap, H. Oschkinat, H.J.M. de Groot, A 3-D model of solid self-assembled chlorophyll $a / \mathrm{H}_{2} \mathrm{O}$ from multispin labeling and MAS NMR 2D dipolar correlation spectroscopy in high magnetic field, J. Magn. Reson. 155 (2002) 1-14.

[13] A. Lesage, D. Sakellariou, S. Steuernagel, L. Emsley, Carbon-proton chemical shift correlation in solid-state NMR by through-bond multiple-quantum spectroscopy, J. Am. Chem. Soc. 120 (1998) 13194-13201.

[14] A. Lesage, L. Emsley, Through-bond heteronuclear single-quantum correlation spectroscopy in solid-state NMR, and comparison to other through-bond and through-space experiments, J. Magn. Reson. 148 (2001) 449-454.

[15] B. Elena, A. Lesage, S. Steuernagel, A. Böckmann, L. Emsley, Proton to carbon-13 INEPT in solid-state NMR spectroscopy, J. Am. Chem. Soc. 127 (2005) 1729617302.

[16] K. Mao, M. Pruski, Directly and indirectly detected through-bond heteronuclear correlation solid-state NMR spectroscopy under fast MAS, J. Magn. Reson. 201 (2009) 165-174.

[17] Y. Ishii, R. Tycko, Sensitivity enhancement in solid state ${ }^{15} \mathrm{~N}$ by indirect detection with high-speed magic angle spinning, J. Magn. Reson. 142 (2000) 199-204.

[18] D.H. Zhou, G. Shah, C. Mullen, D. Sandoz, C.M. Riensta, Proton-detected solidstate NMR spectroscopy of natural-abundance peptide and protein pharmaceuticals, Angew. Chem. Int. Ed. 48 (2009) 1253-1256.

[19] S.M. Althaus, K. Mao, J.A. Stringer, T. Kobayashi, M. Pruski, Indirectly detected heteronuclear correlation solid-state NMR spectroscopy of naturally abundant ${ }^{15} \mathrm{~N}$ nuclei, Solid State Nucl. Magn. Reson. 57-58 (2014) 17-21.

[20] T. Kobayashi, Y. Nishiyama, M. Pruski, Heteronuclear correlation solid-state NMR spectroscopy with indirect detection under fast magic-angle spinning, in: P. Hodgkinson (Ed.), Modern Methods in Solid-State NMR: A Practitioner's Guide, 2018, pp. 1-38.

[21] Hyperpolarization Methods in NMR Spectroscopy, Springer, 2013, pp, 1-304.

[22] A. Lesage, M. Lelli, D. Gajan, M.A. Caporini, V. Vitzthum, P. Miéville, J. Alauzun, A. Roussey, C. Thieuleux, A. Mehdi, G. Bodenhausen, C. Copéret, L. Emsley, Surface enhanced NMR spectroscopy by dynamic nuclear polarization, J. Am. Chem. Soc. 132 (2010) 15459-15461.

[23] M. Lelli, D. Gajan, A. Lesage, M.A. Caporini, V. Vitzthum, P. Miéville, F. Héroguel, F. Rascón, A. Roussey, C. Thieuleux, M. Boualleg, L. Veyre, G. Bodenhausen, C. 
Copéret, L. Emsley, Fast characterization of functionalized silica materials by silicon-29 surface-enhanced NMR spectroscopy using dynamic nuclear polarization, J. Am. Chem. Soc. 133 (2011) 2104-2107.

[24] A. Zagdoun, G. Casano, O. Ouari, G. Lapadula, A.J. Rossini, M. Lelli, M. Baffert, D. Gajan, L. Veyre, W.E. Maas, M. Rosay, R.T. Weber, C. Thieuleux, C. Coperet, A. Lesage, P. Tordo, L. Emsley, A slowly relaxing rigid biradical for efficient dynamic nuclear polarization surface-enhanced $\mathrm{nmr}$ spectroscopy: expeditious characterization of functional group manipulation in hybrid materials, J. Am. Chem. Soc. 134 (2012) 2284-2291.

[25] T. Kobayashi, F.A. Perras, U. Chaudhary, I.I. Slowing, W. Huang, A.D. Sado, M. Pruski, Improved strategies for DNP-enhanced 2D ${ }^{1} \mathrm{H}-\mathrm{X}$ heteronuclear correlation spectroscopy of surfaces, Solid State Nucl. Magn. Reson. 87 (2017) 38-44.

[26] C.E. Lyon, J.A. Jones, C. Redfield, C.M. Dobson, P.J. Hore, Two-dimensional ${ }^{15} \mathrm{~N}-{ }^{1} \mathrm{H}$ photo-CIDNP as a surface probe of native and partially structured proteins, J. Am. Chem. Soc. 121 (1999) 6505-6506.

[27] A. Sekhar, S. Cavagnero, EPIC- and CHANCE-HSQC: two ${ }^{15} \mathrm{~N}-$ photo-CIDNPenhanced pulse sequences for the sensitive detection of solvent-exposed tryptophan, J. Magn. Reson. 200 (2009) 207-213.

[28] J.H. Lee, A. Sekhar, S. Cavagnero, ${ }^{1} \mathrm{H}$-detected ${ }^{13} \mathrm{C}$ photo-CIDNP as sensitivity enhancement tool in solution NMR, J. Am. Chem. Soc. 133 (2011) 8062-8065.

[29] M.J. Zysmilich, A. McDermott, Photochemically induced dynamic nuclear polarization in the solid-state $15 \mathrm{~N}$ spectra of reaction centers from photosynthetic bacteria Rhodobacter sphaeroides R-26, J. Am. Chem. Soc. 116 (1994) 8362-8363.

[30] J. Matysik, A. Diller, E. Roy, A. Alia, The solid-state photo-CIDNP effect, Photosynth. Res. 102 (2009) 427-435.

[31] J.C. Zill, M. Kansy, R. Goss, L. Köhler, A. Alia, C. Wilhelm, J. Matysik, PhotoCIDNP in the reaction center of the diatom Cyclotella meneghiniana observed by ${ }^{13}$ C MAS NMR, Z. Phys. Chem. 231 (2017) 347-367.

[32] J.C. Zill, Z. He, M. Tank, B.H. Ferlez, D.P. Canniffe, Y. Lahav, P. Bellstedt, A. Alia, I. Schapiro, J.H. Golbeck, D.A. Bryant, J. Matysik, ${ }^{15} \mathrm{~N}$ photo-CINDP MAS NMR analysis of reaction centers of Chloracidobacterium thermophilum, Photosynth. Res. 137 (2018) 295-305.

[33] J.C. Zill, M. Kansy, R. Goss, A. Alia, C. Wilhelm, J. Matysik, ${ }^{15} \mathrm{~N}$ photo-CIDNP MAS NMR of both photosystems and magnetic field dependent ${ }^{13} \mathrm{C}$ photo-CIDNP MAS NMR in Photosystem II of diatom Phaeodactylum tricornutum online Photosynth. Res. (2018), https://doi.org/10.1007/s11120-018-0578-9.

[34] S.S. Tamarath, J. Heberle, P. Hore, T. Kottke, J. Matysik, Solid-state photo-CINDP effect observed in phototropin LOV1-C57S by ${ }^{13} \mathrm{C}$ magic-angle spinning NMR spectroscopy, J. Am. Chem. Soc. 132 (2010) 15542-15543.

[35] G. Jeschke, J. Matysik, A reassessment of the origin of photochemically induced dynamic nuclear polarization effects in solids, Chem. Phys. 294 (2003) 239255.

[36] D. Sosnovsky, G. Jeschke, J. Matysik, H.-M. Vieth, K.L. Ivanov, Level crossing analysis of chemically induced dynamic nuclear polarization: towards a common description of liquid-state and solid-state cases, J. Phys. Chem. 144 (2016) 144202-144217.

[37] B.E. Bode, S.S. Tamarath, K.B. Sai Sankar Gupta, A. Alia, G. Jeschke, J. Matysik, The Solid-State Photo-CIDNP Effect and Its Analytical Application, Springer, 2013, pp. 105-121.

[38] E.A.M. Schulten, J. Matysik, A. Alia, S. Kiihne, J. Raap, J. Lugtenburg, P. Gast, A.J. Hoff, H.J.M. de Groot, ${ }^{13} \mathrm{C}$ MAS NMR and Photo-CIDNP reveal a pronounced asymmetry in the electronic ground state of the Special Pair of Rhodobacter sphaeroides reaction centers, Biochemistry 41 (2002) 8708-8717.

[39] E. Daviso, S. Prakash, A. Alia, P. Gast, J. Neugebauer, G. Jeschke, J. Matysik, The electronic structure of the primary electron donor of reaction centers of purple bacteria at atomic resolution as observed by photo-CIDNP ${ }^{13} \mathrm{C}$ NMR, Proc. Natl. Acad. USA 106 (2009) 22281-22286.

[40] S.S. Tamarath, B. Bode, S. Prakash, K.B. Sai Sankar Gupta, A. Alia, G. Jeschke, J. Matysik, Electron spin density distribution in the special pair triplet of Rhodobacter sphaeroides R26 revealed by magnetic field dependence of the solid-state photo-CIDNP effect, J. Am. Chem. Soc. 134 (2012) 5921-5930.

[41] P. Bielytskyi, D. Gräsing, K.R. Mote, K.B. Sai Sankar Gupta, S. Vega, P.K. Madhu, A. Alia, J. Matysik, ${ }^{13} \mathrm{C} \rightarrow{ }^{1} \mathrm{H}$ transfer of light-induced hyperpolarization allows for selective detection of protons in frozen photosynthetic reaction center, J. Magn. Reson. 293 (2018) 82-91.

[42] S. Prakash, A. Alia, P. Gast, H.J.M. de Groot, G. Jeschke, J. Matysik, ${ }^{13} \mathrm{C}$ Chemical shift map of the active cofactors in photosynthetic reaction centers of Rhodobacter sphaeroides revealed by photo-CIDNP MAS NMR, Biochemistry 46 (2007) 8953-8960.

[43] S. Schochat, T. Arlt, C. Francke, P. Gast, P.I. Vannoort, S.C.M. Otte, H.P.M. Schelvis, S. Schmidt, E. Vijgenboom, J. Vriez, W. Zinth, A.J. Hoff, Spectroscopic characterization of reaction centers of the (M)Y210W mutant of the photosynthetic bacterium of Rhodobacter sphaeroides, Photosynth. Res. 40 (1994) 55-66.

[44] M.Y. Okamura, R.A. Isaacson, G. Feher, Primary acceptor in bacterial photosynthesis - obligatory role of ubiquinone in photoactive reaction centers of Rhodopseudomonas sphaeroides, Proc. Natl. Acad. Sci. USA 72 (1975) 3491-3495.

[45] M.R. Fischer, H.J.M. de Groot, J. Raap, C. Winkel, A.J. Hoff, J. Lugtenburg, ${ }^{13} \mathrm{C}$ magic angle spinning NMR-study of the light-induced and temperature- dependent changes in Rhodobacter sphaeroides $\mathrm{R}-26$ reaction centers enriched in $4^{\prime}-{ }^{13} \mathrm{C}$ tyrosine, Biochemistry 31 (1992) 11038-11049.

[46] J. Matysik, G. Alia, T. Hollander, P. Egorova-Zachernyuk, H.J.M. Gast, de Groot Sample illumination and photo-CIDNP in a magic-angle spinning NMR probe, Indian J. Biochem. Biophys. 37 (2000) 418-423.

[47] E. Daviso, G. Jeschke, J. Matysik, Photochemically induced dynamic nuclear polarization (Photo-CIDNP) magic-angle spinning NMR, Springer, The Netherlands, 2008, pp. 385-399.

[48] E. Vinogradov, P.K. Madhu, S. Vega, Phase modulated Lee-Goldburg magic angle spinning proton nuclear magnetic resonance experiments in solid state: a bimodal Floquet theoretical treatment, J. Chem. Phys. 115 (2001) 89839000.

[49] S. Paul, R.S. Thakur, M. Goswami, A.C. Sauerwein, S. Mamone, M. Concistrè, H. Förster, M.H. Levitt, P.K. Madhu, Supercycled homonuclear dipolar decoupling sequences in solid-state NMR, J. Magn. Reson. 197 (2009) 14-19.

[50] C. Coelho, J. Rocha, P.K. Madhu, L. Marfa, Practical aspects of Lee-Goldburg based CRAMPS techniques for high-resolution ${ }^{1} \mathrm{H}$ NMR spectroscopy in solids: implementation and applications, J. Magn. Reson. 194 (2007) 264-282.

[51] R.S. Thakur, N.D. Kurur, P.K. Madhu, Swept-frequency two-pulse phase modulation for heteronuclear dipolar decoupling in solid-state NMR, Chem. Phys. Lett. 426 (2006) 459-463.

[52] D. Marion, K. Wüthrich, Application of phase sensitive two-dimensional correlated spectroscopy (COSY) for measurement of ${ }^{1} \mathrm{H}-{ }^{1} \mathrm{H}$ spin-spin coupling constants in proteins, Biochem. Biophys. Res. Commun. 113 (1983) 967-974.

[53] O.B. Peersen, X. Wu, S.O. Smith, Enhancement of CP-MAS signals by variableamplitude cross polarization. Compensation for inhomogeneous $\mathrm{B}_{1}$ fields, J. Magn. Reson. Ser. A 106 (1994) 127-131.

[54] T. Terao, H. Miura, A. Saika, High-resolution J-resolved NMR spectra of dilute spins in solids, J. Chem. Phys. 75 (1981) 1573-1574.

[55] G. Bodenhausen, D.J. Ruben, Natural abundance nitrogen-15 NMR by enhanced heteronuclear spectroscopy, Chem. Phys. Lett. 69 (1980) 185-189.

[56] S. Prakash, A. Alia, P. Gast, H.J.M. de Groot, G. Jeschke, J. Matysik, Magnetic field dependence of photo-CIDNP MAS NMR of photosynthetic reaction centers of Rhodobacter sphaeroides WT, J. Am. Chem. Soc. 127 (2005) 14290-14298.

[57] K.B. Sai Sankar Gupta, E. Daviso, G. Jeschke, A. Alia, M. Ernst, J. Matysik Spectral editing through laser-flash excitation in two-dimensional photoCIDNP MAS NMR experiments, J. Magn. Reson. 246 (2014) 9-17.

[58] M. Najdanova, D. Gräsing, A. Alia, J. Matysik, Analysis of the electronic structure of the special pair of a bacterial photosynthetic reaction center by ${ }^{13} \mathrm{C}$ photochemically induced dynamic nuclear polarization magic-angle spinning NMR using double-quantum axis, Photochem. Photobiol. 94 (2018) 69-80.

[59] A. Diller, S. Prakash, A. Alia, P. Gast, J. Matysik, G. Jeschke, Signals in solid-state photochemically induced dynamic nuclear polarization recover faster than signals obtained with the longitudinal relaxation time, J. Phys. Chem. B 111 (2007) 10606-10614.

[60] A.N. Appleyard, R.B. Herbert, P.J.F. Henderson, A. Watts, P.J.R. Spooner, Selective NMR observation of inhibitor and sugar binding to the galactose$\mathrm{H}^{+}$symport protein GalP, of Escherichia coli, Biochim. Biophys. Acta 1509 (2000) 55-64.

[61] J.J. Lopez, C. Kaiser, S. Shastri, C. Glaubitz, Double quantum filtering homonuclear MAS NMR correlation spectra: a tool for membrane protein studies, J. Biomol. NMR 41 (2008) 97-104.

[62] A.E. Bennett, R.G. Griffin, J.H. Ok, S. Vega, Chemical shift correlation spectroscopy in rotating solids: radio frequency-driven dipolar recoupling and longitudinal exchange, J. Chem. Phys. 96 (1992) 8624-8627.

[63] Y. Kobori, N. Ponomarenko, J.R. Norris, Time-resolved electron paramagnetic resonance study on cofactor geometries and electronic couplings after primary charge separations in the photosynthetic reaction center, J. Phys. Chem. C 119 (2015) 8078-8088.

[64] A.R. Holzwarth, M.G. Müller, Energetics and kinetics of radical pairs in reaction centers from Rhodobacter sphaeroides. A femtosecond transient absorption study, Biochemistry 35 (1996) 11820-11831.

[65] K.B. Sai Sankar Gupta, A. Alia, H.J.M. de Groot, J. Matysik, Symmetry break of special pair: photochemically induced dynamic nuclear polarization NMR confirms control by nonaromatic substituents, J. Am. Chem. Soc. 135 (2013) $10382-10387$.

[66] T. Egorova-Zachernyuk, B.J. van Rossum, C. Erkelens, H.J.M. de Groot, Characterization of uniformly ${ }^{13} \mathrm{C},{ }^{15} \mathrm{~N}$ labeled bacteriochlorophyll $a$ and bacteriopheophytin $a$ in solution and in solid state: complete assignment of the ${ }^{13} \mathrm{C},{ }^{1} \mathrm{H}$ and ${ }^{15} \mathrm{~N}$ chemical shifts, Magn. Reson. Chem. 46 (2008) 1074-1083.

[67] E. Daviso, A. Alia, S. Prakash, A. Diller, P. Gast, J. Lugtenburg, J. Matysik, G. Jeschke, Electron-nuclear spin dynamics in bacterial photosynthetic reaction center, J. Phys. Chem. C 113 (2009) 10269-10278.

[68] K.B. Sai Sankar Gupta, A. Alia, F. Buda, H.J.M. de Groot, J. Matysik, Bacteriopheophytin $a$ in the active branch of the reaction center of Rhodobacter sphaeroides is not disturbed by the protein matrix as shown by ${ }^{13}$ C photo-CIDNP MAS NMR, J. Phys. Chem. B 117 (2013) 3287-3297.

[69] C. Giessner-Prettre, B. Pullman, Intermolecular nuclear shielding due to the aromatic amino acids of proteins and to porphyrins, J. Theor. Biol. 31 (1971) 287-294. 